\title{
LA INDUSTRIA EDITORIAL ESPAÑOLA ANTE LOS MERCADOS AMERICANOS DEL LIBRO 1892-1936
}

por

\section{ANA MARTÍNEZ RuS}

Universidad Complutense de Madrid

RESUMEN: En este artículo se analiza la proyección editorial en Hispanoamérica desde los años finales del siglo XIX basta la guerra civil. Se abordan las condiciones en que se desarrollaba el comercio de libros con aquellas repúblicas, los problemas que afectaban a la producción, distribución y venta de las obras, y las estrategias desplegadas por editores y libreros para mejorar e intensificar la exportación. La industria librera española era necesariamente exportadora por las limitaciones económicas y culturales del mercado nacional, y por la amplia demanda de veinte países de habla bispana en desarrollo. Aunque siempre fue un comercio beneficioso, los profesionales del libro debieron de bacer frente a la competencia extranjera con la edición de libros en castellano y a las ediciones clandestinas realizadas en los países americanos, así como a las dificultades derivadas de una producción del libro cara y limitada, de un débil sistema de financiación, de una deficiente red de transportes, y de una escasa propaganda de la bibliografía nacional. También se estudia el papel desempeñado por el Estado en la difusión del libro español, sobre todo en relación con el proteccionismo arancelario, que tan perjudicial resultó para la industria editorial.

Palabras clave: Historia de la edición. Exportación de libros. Comercio con Hispanoamérica. Producción bibliográfica.

ABSTRACT: The article analyses the book trade with Latin American from the end of the nineteenth century until the civil war. It addresses the condition of trade with the various Latin American republlics, the problems affecting book production, distribution and sale; and, finally, the strategies adopted by Spanish editors and booksellers to increase exports. The Spanish book industry was necessarily oriented towards exports because of the economic and cultural limitations of the national market, and because of new and high demand from twenty Spanish-speaking countries. Although it was always profitable, the publishers bad to face foreign competition in Spanish-language book production, clandestine publication in Latin Ameri- 
can countries, the difficulties derived from producing expensive books in limited editions, the weakness of financial support, ineffective transport and poor publicity. This article also studies the role of the state in the diffusion of Spanish book, empbasising the importance of protectionism, which proved very damaging to the publishing industry.

KEY WORDS: Publishing. Book export. Latin American trade. Bibliographic production.

A lo largo del primer tercio del siglo XX la industria editorial española se ocupó de los mercados americanos, salida natural a la producción bibliográfica nacional y que desde el siglo pasado recibían publicaciones en castellano editados en Francia, Alemania o Estados Unidos ${ }^{1}$. Este fenómeno de expansión estaba relacionado con el proceso de modernización industrial y comercial provocado por los avances técnicos, la aparición del editor como profesión autónoma diferenciada del comercio de librería, y la formación de sociedades anónimas. El panorama editorial estaba formado por antiguas casas, transformadas en nuevas sociedades anónimas como Hernando (1828), Bailly-Baillière (1848), Reus (1852), Montaner y Simón (1868), Saturnino Calleja (1875), Sopena (1896) o Salvat (1897), y en modernas empresas como Seix Barral, S. A. (1911), Labor, S. A. (1915), Juventud, S. A. (1923), Espasa-Calpe, S. A. (1925) o la Compañía Iberoamericana de Publicaciones (CIAP) (1928), aunque predominaban los editores particulares o las casas familiares como Araluce (1876), Gustavo Gili (1902), Editorial Bauzá (1905), Biblioteca Nueva (1917), Ediciones Morata (1920) o Aguilar (1923). Estas editoriales nuevas o renovadas, situadas principalmente en Madrid y Barcelona, aumentaron la producción bibliográfica, transformaron la industria librera española, y se encargaron de la exportación a Hispanoamérica. La principal característica de estas empresas fue la introducción de capital en el negocio del libro, fruto de los beneficios de la neutralidad española durante la Gran Guerra. Así apareció CALPE, S.A. en 1918 con doce millones de pesetas y Calleja amplió su patrimonio a diez millones. A pesar de este impulso financiero la producción del libro siguió siendo un sector de negocios familiares o de pequeñas compañías más que de grandes sociedades anónimas. El capital prefería otros negocios industriales y bancarios más rentables y seguros que el editorial. De hecho tan sólo en cinco empresas editoriales figuran alguno de los cien grandes capitalistas del país en sus consejos de administración. Este era el caso de Calpe y Reus de Madrid, de las editoriales Catalana y Muntañola de Barcelona, y de la Biblioteca de Amigos del País Vasco de Bil-

1 Para un mayor estudio sobre el comercio de libros con los países americanos vid. MARTINEZ RUS, Ana: La proyección editorial en Hispanoamérica en el primer tercio del siglo XX, Madrid, UCM, Tesina inédita, 1998.

Hispania, LXII/3, núm. 212 (2002) 1021-1058 
bao $^{2}$. Además la imposibilidad de superar los 8.000 ejemplares de tirada (la edición normal era de 3.000 ejemplares) debido a la irregularidad de las ventas impedía la inmovilización de capital para tiradas mayores, y dificultaban la conversión de las casas editoriales en industrias modernas. En este sentido destaca que en los años treinta las editoriales constituidas en sociedades anónimas no pasaran de cuarenta y cinco, aunque la industria editorial estaba formada por más de trescientas casas. Pero, salvo Espasa-Calpe que contaba con dieciséis millones de pesetas y Calleja con quince, estas empresas no poseían grandes patrimonios. Así la Librería y Casa Editorial Hernando disponía de cuatro millones setecientas cincuenta mil pesetas de capital, la Editorial Castro y Ramón Sopena de tres millones de pesetas, la Editorial Reus de dos millones, las editoriales Labor y Salvat contaban con un millón doscientas mil pesetas, la Editorial Juventud de un millón de pesetas, la CIAP de seiscientas mil pesetas, mientras que Cenit y la Revista de Occidente sólo tenían cien mil pesetas ${ }^{3}$. En cualquier caso en las primeras décadas del siglo XX se consolidó el mercado empresarial del libro y la especialización de publicaciones. La industrialización de la producción del libro entrañaba un verdadero riesgo de superproducción, teniendo en cuenta la lenta salida al mercado. En este sentido la necesidad de vender aumentó la competencia entre las empresas en la búsqueda de nuevas estrategias editoriales, que definían la economía del libro, para captar a nuevos y más lectores en España y América entre colectivos alejados tradicionalmente de la lectura -obreros, mujeres, jóvenes-, en relación con los mayores índices de alfabetización, la mayor concienciación social y política, y la progresiva democratización de la sociedad. A este cambio cualitativo y cuantitativo contribuyeron los nuevos procedimientos de impresión y de composición tipográfica, que perfeccionaron los tradicionales del siglo pasado y abarataron los costes, así como los modernos sistemas de comercialización (ventas a plazos, por suscripción, y por catálogos) y de publicidad.

Debido a la importancia que las relaciones culturales cobraron en la diplomacia de entreguerras, el libro se convirtió en el principal vehículo e instrumento para lograr prestigio y peso en el ámbito internacional. El intercambio de publicaciones pasó a ser un elemento fundamental de la acción cultural para dar a conocer el desarrollo literario, científico y técnico de una nación. A lo largo del siglo XX España ha pretendido recuperar la presencia y la influencia en Iberoamérica a través de lazos culturales y comerciales ${ }^{4}$. El restablecimiento

2 Vid. Garcia Delgado, José Luis, Roldan, Santiago y MuÑoz, Juan: La consolidación del capitalismo en España 1914-20, Madrid, 1974, 2 vol., p. 424 (sector de Artes Gráficas).

3 Vid. el capítulo de Artes Gráficas en el Anuario Financiero y de Sociedades Anónimas de España, Madrid, 1931-1936.

4 Vid. los interesantes trabajos de Delgado GomeZ-Escalonilla, Lorenzo: «Un nuevo elemento de la política exterior" en Imperio de papel. Acción cultural y política exterior durante el primer franquismo, pp. 9-70.Y la introducción y el capítulo: «Comunidad hispanoamericana e identidad 
de relaciones con los nuevos países hispanoamericanos se inició en 1836 con la firma del Tratado de paz y amistad entre España y Méjico, y finalizó con el firmado en 1894 con Honduras. A estos acuerdos de normalización diplomática le siguieron algunos tratados sobre protección intelectual. El reencuentro se inició en los últimos decenios del siglo XIX con el modernismo literario y con los actos del IV Centenario del descubrimiento de América, impulsados por la Unión Iberoamericana, creada en la Universidad de Madrid en 1885 para fomentar el acercamiento y cooperación de los países hispanos, que contó con subvención oficial y con el apoyo de la mayoría de los gobiernos americanos ${ }^{5}$ : «El movimiento de aproximación entre España y América, iniciado con motivo del Centenario de Colón, es un elemento que puede ayudar a resolver el arduo problema de nuestra exportación de libros a América. La actitud y buenas disposiciones en que aparecen estar los americanos que nos han visitado, deben utilizarse antes de que se enfríen los entusiasmos que han despertado en los últimos festejos. La reconquista de aquel mercado para nuestros libros es asunto de colosal importancia» ${ }^{6}$.

La vocación americanista nació ligada a proyectos políticos regeneracionistas y a intereses económicos catalanes ${ }^{7}$. El acercamiento a los países hispanos - bajo una identidad cultural común - cobró fuerza en la reorientación de las relaciones exteriores españolas tras la derrota de 1898, como sólida alternativa a la crisis nacional y al desprestigio internacional. La intención mercantil y cultural culminó con la celebración del Congreso Nacional del Comercio en Ultramar en 1923, donde el libro español y su difusión ocupó un lugar destacado por la importancia económica del mismo en aquellos vastos mercados de habla hispana, y por su carácter de mercancía de penetración, facilitando la apertura como incentivo indirecto a otros productos comerciales del país. Sin olvidar la importancia de la influencia cultural, tan bien entendida por los franceses, para alcanzar una posición política y económica fuerte en aquellos países, sigilosamente, sin despertar hostilidades. Además, la debilidad comercial y financiera de España en el continente americano frente a las potencias europeas obligaba a reforzar la comunidad idiomática y cultural iberoamericana, favoreciendo el

cultural. La perspectiva española», en Diplomacia franquista y política cultural bacia Iberoamérica, Madrid, 1988, pp. 7-36.

5 Vid. el sugerente ensayo de RAMA, Carlos: Historia de las relaciones culturales entre España y América Latina: S. XIX, Madrid, 1982.

6 Escrito de José Ruiz y José Lázaro dirigido al gremio de libreros y editores en 1892 con motivo de la elebración del Congreso Literario, recogido en GUTIERREZ JIMENEZ, Rafael: La producción literaria en España y el comercio de exportación en América, Madrid, 1893, p. V.

7 Vid. MAINER, Juan Carlos: «Un capítulo regeneracionista: el hispanoamericanismo (18921923)» en La doma de la quimera, Barcelona, 1988. Asimismo destaca el trabajo de VeLEZ, Pilar: «El período de madurez del americanismo en España. Proyectos y realizaciones», en HUGUET SANTOS, Monserrat, NiÑo, Antonio y Perez HerRero, Pedro (Coords.): La formación de la imagen de América Latina en España, 1898-1989, Madrid, 1992, pp. 171-187.

Hispania, LXII/3, núm. 212 (2002) 1021-1058 
intercambio de publicaciones, aunque como veremos la industria editorial española no pudo aprovechar esta circunstancia en su totalidad. De este modo el libro en castellano formó parte del programa de expansión económica y cultural en Hispanoamérica para reforzar la presencia española.

«(...) la difusión de los libros y revistas en lengua española (...) constituyen el medio quizás más adecuado y poderoso, no ya, como es obvio para extender y arraigar nuestra cultura en los países hispanoamericanos, sino para favorecer nuestra expansión económica; porque es un hecho innegable, puesto de relieve en múltiples ocasiones, que al penetrar en los mercados la producción editorial abre con la sutil fuerza de su espiritualidad anchas vías por donde afluyen luego como séquito obligado todos los demás productos con que la civilización y la industria puesta a su servicio labran el bienestar y la riqueza de los pueblos en nuestros días (...).

Porque el libro, harto se ha dicho y repetido, no es un artículo cuyo valor e importancia puedan medirse por las cifras estadísticas del movimiento comercial; es, a la par que un objeto de comercio, factor moral cuya eficacia como vehículo de nuestra cultura recae visiblemente y en no escasa medida en provecho de la expansión económica»8.

\section{LA PRODUCCIÓN DEL LIBRO EN ESPAÑA}

El proteccionismo arancelario, que caracterizó la economía española del primer tercio del siglo XX, gravó las materias primas y los bienes de equipo de procedencia extranjera, imprescindibles en la producción de libros. No sólo afectaba a un producto básico como el papel sino también a la maquinaria de imprimir, a los tejidos para encuadernar, al oro enrollado, y al filetaje de bronce. Esta circunstancia resultaba tan perjudicial para la industria del libro como la cuestión del papel, y más si tenemos en cuenta que en España no se producían estas máquinas ni estos materiales necesarios en la confección de los libros. Tan sólo había una fábrica de tejidos con un muestrario muy reducido. En estos casos el arancel era absurdo puesto que no había ninguna industria nacional que proteger, su única finalidad era recaudar impuestos. Así lo denunció la Federación Española de Productores, Comerciantes y Amigos del Libro de Madrid en 1921 ante la Junta de Aranceles y Valoraciones ${ }^{9}$, y se volvió a insistir en la Conferencia Nacional del Libro de 1927, donde se solicitó una rebaja de $50 \%$ en los derechos arancelarios en las partidas 578,579 y 580 referidas a la

\footnotetext{
8 «Organización de las Cámaras de Comercio Españolas en Ultramar con relación al régimen de propiedad literaria y a la difusión especial del libro español», en Primer Congreso Nacional del Comercio Español en Ultramar, Sección $1^{\text {a }}$, Fascículo ${ }^{\circ}$ 6, Madrid, 1923, p. 3. AGA, Sección de Asuntos Exteriores, Caja ${ }^{\circ} 5416$.

9 Informe recogido en Camara Oficial del Libro de Barcelona: Memoria ... correspondiente al ejercicio 1921-22, pp. 121-124.
} 
maquinaria de impresión y la anulación del aumento del $20 \%$ sobre los derechos del Arancel de 1922, establecido por Real Decreto de 9 de julio de 1926. Esta revisión arancelaria dirigida a la protección de la industria textil y metalúrgica, encareció notablemente la importación de las máquinas para imprenta, litografía, encuadernación y para demás ramas de Artes gráficas, al igual que las piezas sueltas de dicha maquinaria, contempladas en la partida 581. Igualmente reclamaron franquicia aduanera para el oro enrollado, y una rebaja de las tarifas (2,75 ptas.) de los tejidos de encuadernación porque las carencias de los nacionales obligan a la importación para poder competir con las encuadernaciones extranjeras en el mercado americano, donde preferían el libro encuadernado ya que allí resultaba más cara la encuadernación por la mano de obra $^{10}$. La política arancelaria no contribuyó al desarrollo de la industria editorial ni favoreció la expansión del libro español. De hecho en 1913 en España se introdujeron libros e impresos en castellano por valor de 1.417 .914 pesetas, mientras que el papel de ediciones (de 51 gramos en adelante) no pasó de 284.142 pesetas $^{11}$. A pesar de las promesas gubernamentales de protección para el libro y fomento de la exportación, y de la retórica oficial sobre el estrechamiento de relaciones económicas y culturales con Hispanoamérica, los gravámenes impuestos sobre la importación de las primeras materias necesarias para el desarrollo de la industria del libro, colocaban su comercialización en los mercados americanos en inferioridad frente a la concurrencia extranjera.

«(...) el Gobierno debiera hacer y no hace: (...) rebajar las tarifas de los aranceles referentes al papel, tipos y maquinaria de imprenta y efectos de encuadernación, para que sea posible que los editores españoles puedan competir en América, y aun en nuestra península, con los editores de París, Leipzig y Chicago»12.

«(...) la superchería del proteccionismo hace que paguemos por las máquinas de imprimir y encuadernar la tarifa arancelaria correspondiente a automóviles de lujo; y que el papel fabricado en España cueste no el precio regular, según se vende en todo el mundo, sino el equivalente a la suma del precio del papel extranjero, del transporte y de los derechos de aduanas» 13 .

Ante esta situación los editores reclamaron una ayuda económica estatal que favoreciese la exportación del libro español en condiciones competitivas, bien de forma indirecta con exenciones o rebajas de cuotas, o bien directamente a través de subvenciones. Respecto a la exención solicitaron constantemente

$10 \mathrm{M}^{\circ}$ De Trabajo, Comercio e Industria: Conferencia Nacional del Libro, Madrid, 1927, pp. 26 y 72-82. Y Compendio de conclusiones recogidas de los informes presentados para la Conferencia Nacional del Libro, pp. 5 y 6.

11 Datos extractados del Informe ya mencionado de la Cámara Oficial de Barcelona a la Junta de Aranceles el 1 de septiembre de 1921, en Memoria ... correspondiente al ejercicio 1921-22, p. 118.

12 «El Ministerio de Fomento y el comercio de libros» en Bibliografía Española, octubre de 1911 , pp. 73-74.

13 «Ediciones extranjeras de libros españoles» en Bibliografía ..., abril de 1913, pp. 25-26.

Hispania, LXII/3, núm. 212 (2002) 1021-1058 
la devolución o supresión de los derechos arancelarios. Además la devolución de los derechos arancelarios se adecuaba al sistema de compensaciones directas para fomento de las exportaciones, regulado en la base $8^{a}$ de la ya mencionada Ley de protección a las industrias de 1917 , así como al apartado d/, base $3^{\text {a }}$ sobre compensaciones arancelarias del Real Decreto de protección de las industrias nacionales de 30 de abril de 1924. Y así lo solicitó nuevamente el Presidente de la Cámara Oficial de Barcelona, Mariano Viada, al Presidente del Directorio Militar, Primo de Rivera, ya que el precio del papel había aumentado entre un $20 \%$ o $25 \%$ y el coste por embalaje, transportes, fletes, seguros y gastos de Aduanas recargaban los libros entre un $10 \%$ y un $12 \%$, pero tampoco resultó. Asimismo los editores exigieron la anulación del recargo del 100\% sobre la contribución que pagaban los editores por exportar, según Real Orden del Ministerio de Hacienda de 18 de noviembre de 1919, pero que desde los Reales Decretos de 1922 habían pasado a percibir las Cámaras Oficiales del Libro para sufragar el coste de la revista bibliográfica y profesional, Bibliografía General Española e Hispanoamericana. Resultaba paradójico y contradictorio que se pretendiera la difusión y venta del libro español en los mercados hispanos, al mismo tiempo que los propios exportadores de libros tenían que abonar este recargo ${ }^{14}$. En relación con las subvenciones, la reivindicación de primas a la exportación era una vieja aspiración de los editores para favorecer la venta de libros en América y compensar los altos derechos arancelarios que pesaba sobre la industria del libro. En 1928 se establecieron las primas a la exportación de libros en el artículo 23 y 24 del R. D. de 24 de agosto que aprobaba el reglamento del Comité Regulador de la Industria del Papel. Este organismo se había creado meses antes (R. D. 11 de mayo) para compensar a la industria papelera del perjuicio provocado por los reducidos derechos arancelarios concedidos a la importación del papel de prensa en 1921. Se mantenía el trato de privilegio para la prensa pero, debido al carácter de industria protegida, el Estado auxiliaría a los fabricantes de papel, y esta ayuda a su vez repercutiría en los editores exportadores que estuviesen asociados o sindicados. Pero, debido a la escasa participación de los editores en el Sindicato Exportador del Libro Español madrileño, y en el Consorcio Exportador del Libro Español catalán, en el reglamento reformado del Comité en febrero de 1931, se estableció que también podían recibir las primas a la exportación los editores individuales, a través de las Cámaras del Libro's. Pero, después de tres años, en 1932 se suprimieron las primas a la exportación por una bonificación sustitutiva en favor de la propaganda colectiva del libro español en España y América.

14 Vid. Calvo Sotelo, Leopoldo: Memoria sobre el libro español en América, Madrid, 1927, p. 86. El libro español en América, pp. 88-89. Y «Orientaciones convenientes a la Cámara del Libro y medios para desarrollar la expansión del libro español» (1926), en Bibliografía General Española e Hispanoamericana, Madrid, marzo de 1927, p. 26. Asimismo M $^{\circ}$ DE TRABAJO..., Conferencia $\mathrm{Na-}$ cional ..., p. 27, y Compendio de conclusiones ..., p. 7.

is BELTRAN, Francisco: El libro y la imprenta, Madrid, 1931, pp. 72 y 73. 
Igualmente la fabricación del papel y su precio condicionaron el desarrollo de la producción editorial española a lo largo de este período. La constitución en 1901 de La Papelera Española en Bilbao y la fuerte protección arancelaria desarrollaron la industria papelera nacional. Esta empresa con vocación monopolista impulsó la Central Papelera en 1914 para organizar la venta del papel con la participación del resto de fabricantes, y la Sociedad Cooperativa de Fabricantes de Papel en 1919 para conseguir la integración vertical, abarcando todo el proceso productivo. La sociedad papelera dirigida por Nicolás $\mathbf{M}^{\mathrm{a}}$ de Urgoiti garantizó la autosuficiencia pero, a unos precios muy elevados ${ }^{16}$. A principios de siglo el papel ordinario en España costaba 45 céntimos de peseta el kilo mientras que en Italia, Francia, Inglaterra, Alemania y Estados Unidos oscilaba entre 22 y 30 céntimos por kilo, y en las restantes clases de papel la diferencia con los papeles extranjeros llegaba al $40 \%{ }^{17}$. Esta situación perjudicaba notablemente la industria y el comercio del libro en el exterior. El libro español no podía competir con el precio ofrecido por los países extranjeros en Hispanoamérica: «(...) el principal obstáculo que se interpone entre los industriales españoles y los mercados de Ultramar consiste en la clase y el precio del papel» ${ }^{18}$. Además la cuestión del papel resultaba irritante para los editores en relación con el tratamiento arancelario de favor otorgado al papel destinado a periódicos y revistas por motivos políticos y por la presión de la opinión pública expresada en la prensa nacional. El arancel de 1911 gravaba la importación del papel para periódicos (partida 409) con 8,50 pesetas los 100 kilos y el empleado para libros (partida 410) con 18 pesetas. Este agravio comparativo se acentuó con la Ley del anticipo reintegrable concedida a la prensa por R. D. de 19 de octubre de 1916 para paliar la subida del precio del papel durante la Gran Guerra por la escasez de materias primas y el encarecimiento de los fletes marítimos. El auxilio estatal consistía en el adelanto a las empresas periodísticas del dinero suficiente para cubrir la diferencia entre los precios de 1914 y los establecidos por las sucesivas alzas. Los editores reclamaron la misma subvención de la Hacienda Pública en la adquisición de papel para impresión de libros, pero tan sólo consiguieron la prohibición temporal de la exportación de pastas,

16 Sobre el proceso de concentración de la industria papelera española impulsado por La Papelera, y sus repercusiones en el mundo de la prensa y en la industria editorial destaca la biografía de su promotor escrita por CABRERA, Mercedes: La industria, la prensa y la política. Nicolás María de Urgoiti (1869-1951), Madrid, 1994.

17 Crónica de la I Asamblea Nacional de Editores y Libreros, Barcelona, 1909, p. 109.

18 Informe de la Cámara Oficial del Libro de Barcelona a la Junta de Aranceles y Valoraciones de 1 de septiembre de 1921 con motivo de la revisión arancelaria, en Memoria ... correspondiente al ejercicio 1921-22, p. 118. Nicolás $\mathrm{M}^{a}$ de Urgoiti en su opúsculo: El papel en su aspecto arancelario, Madrid, 1911, p. 70, aseguraba que los derechos arancelarios no eran utilizados por los fabricantes de papel en su beneficio y, prometía que entregarían papel aún perdiendo dinero a los editores al mismo precio que el de París para favorecer la exportación de libros a América. 
papel, cartón y cartulinas R. O. de mayo de $1917^{19}$. La neutralidad española había favorecido la exportación masiva de papeles en condiciones muy rentables, desabasteciendo el mercado interior y triplicando su importe. La falta y la carestía del papel en la postguerra obligó al Ministerio de Hacienda a autorizar en 1920 la libre importación de papel para impresiones temporalmente, ante la constantes protestas de los periodistas y de la Federación Española de Productores, Comerciantes y Amigos del Libro para «contrarrestar la grave crisis que actualmente viene atravesando la Prensa profesional y la industria del Libro de toda España» ${ }^{20}$. La crisis de la industria española y el déficit de la balanza comercial que siguieron al final de la guerra determinó que a lo largo de 1921 se derogaran las prohibiciones a la exportación y suprimieran las franquicias a la importación, además de la inmediata implantación de un nuevo Arancel de Aduanas, al Arancel transitorio de 1921 y el definitivo Arancel Cambó de 1922 , que volvió a encarecer la importación de papel ${ }^{21}$. Pero, a las empresas periodísticas y revistas se les concedió un régimen de excepción con los Reales Decretos de 26 de marzo y 15 de julio de 1921, y se mantuvo con las Reales Ordenes de 26 de agosto de 1926, 28 de diciembre de 1923 y 12 de septiembre de 1925 y Real Decreto de 1929, que permitía importar papel del extranjero para su exclusivo consumo en condiciones muy ventajosas: 0,50 pesetas los 100 kilos de papel alisado o satinado de 42 a 62 gramos el metro cuadrado; 5 ptas. los $100 \mathrm{~kg}$. de papel satinado de 63 a 120 gramos; y 10 ptas. los $100 \mathrm{Kg}$. de papel couché de 80 a 130 gramos. Por el contrario la importación de las distintas clases del papel de edición de libros pagaban según las partidas y las tarifas entre 60 y 20 pesetas los 100 kilos (partida 1027); entre 75 y 25 ptas. los cien kilos (partida 1028); y 113 y 45 ptas. los 100 kilos (partida 1029) ${ }^{22}$.

«(...) mientras que se bajan los derechos arancelarios para los papeles en que se imprimen los periódicos, se suben las clases de papel en que se imprimen los

19 Sobre los problemas de abastecimiento y encarecimiento del papel durante la I Guerra Mundial en la industria editorial, así como la solicitud de una auxilio estatal como el anticipo reintegrable para la prensa vid. "La cuestión del papel», "Justa y legítima petición» y "La escasez del papel» en Bibliografía ..., septiembre de 1916, pp. 77-79, noviembre de 1916, pp. 93-95, y mayo de 1917, pp. 49-52. Asimismo sobre los conflictos del papel con la prensa y los editores destaca el artículo de EsCAR LAGADA, Manuel: «Mientras la Paz» en La Gaceta de las Artes Gráficas, del Libro y de la Industria del Papel, Barcelona, marzo de 1930, pp. 37-41.

20 Real Orden publicada en La Gaceta de Madrid el 5 de agosto de 1920.

21 Vid. Pelecha ZozoYA, Félix: El proteccionismo industrial en España (1914-1931), Barcelona, 1987. «La acentuación del proteccionismo arancelario» en GARCIA DELGADO, José Luis, ROLDAN, Santiago y MUÑOZ, Juan: La formación de la sociedad capitalista en España 1914-20, Madrid, 1973, vol. 2, pp. 379-393. SERRANO SANZ, José $\mathrm{M}^{\mathrm{a}}$ : «La política arancelaria española al término de la Primera Guerra Mundial: proteccionismo, arancel Cambó y tratados comerciales» en GARCIA DELGADO, J. L. (Ed.): La crisis de la Restauración, Madrid, 1986, pp. 199-216. $72-75$.

22 Vid. «El problema del papel en el Parlamento» en Bibliografía General..., mayo de 1932, pp. 
libros al objeto de reservar a las empresas papeleras españolas el consumo de su producción, y estas empresas papeleras para resarcirse de las pérdidas que les ocasiona la competencia del papel extranjero destinado al uso de periódicos, eleva los precios del papel destinado a usos editoriales» 23 .

Para compensar los precios del papel de libros se estableció por Reales Decretos de 15 de febrero y 12 de mayo de 1922 un sistema de bonificaciones para el consumo de papel de edición. Los fabricantes nacionales de papel debían conceder a los editores un descuento en los precios de los papeles tipos para libros y en todas las demás clases de papel para imprimir, equivalente al $25 \%$ de los derechos que tenían que pagar las clases similares de papel importadas del extranjero; un $40 \%$ cuando los libros se destinasen a la exportación, principalmente a los países hispanoamericanos; y un $60 \%$ cuando fuesen libros exportados por sindicatos de exportación reconocidos por las Cámaras Oficiales del Libro. Asimismo en los Decretos mencionados, referidos a la organización corporativa de los productores y comerciantes del libro, se fijó el arbitrio de 1 céntimo por kilo de papel consumido para el sostenimiento de las Cámaras Oficiales del Libro, que debían satisfacer los fabricantes nacionales de papel y los importadores de papel. Y se acordó que una delegación del Comité Oficial del Libro, compuesta por un vocal representante de los editores, otro de los fabricantes de papel, y el Jefe de la Sección de Estudios Arancelarios de la Dirección General de Aduanas, fijarían mensualmente los precios de los papeles establecidos para el libro, considerando para tales precios los que resulten entre la media de sus similares de Alemania, Inglaterra, Suecia y Francia, agregando los gastos medios desde el origen hasta colocar el papel en vagón ferrocarril en los puertos de Pasajes o Barcelona y los derechos de Aduanas, con los recargos que correspondiesen, según el trato arancelario que se les aplicaba. Estas medidas no acabaron con las continuas protestas y críticas de los editores a La Papelera, ya que el papel se convirtió en un problema endémico para el libro español. En este sentido volvieron a pedir igualdad en el trato arancelario para el papel de prensa y el de edición de libros, sin conseguirlo en la Conferencia $\mathrm{Na}$ cional del Libro de 1927. Consideraban que la concentración de la industria del papel española —el trust del papel — resultaba perturbadora porque afectaba a casi la totalidad del sector y no conseguía una mayor perfección en los productos, ni una máxima reducción en los precios. De hecho en todas las memorias consulares de $1922^{24}$ se insistía en la necesidad de rebajar el importe del papel

${ }^{23}$ Memoria consular de Bolivia, capítulo 5, p. 2. AGA, Sección de Asuntos Exteriores, Caja $\mathrm{n}^{\circ} 1275$

24 Estas Memorias respondían al Cuestionario sobre la situación del libro español en los distintos países americanos, enviado por la Oficina de Relaciones Culturales Española a instancias de la Cámara Oficial del Libro de Barcelona en 1922 por R. D. de 24 de julio, debido al desconocimiento existente sobre aquellos mercados, sus necesidades y sobre el volumen de libros exportados por la industria editorial nacional.

Hispania, LXII/3, núm. 212 (2002) 1021-1058 
para abaratar el precio del libro español en relación con las publicaciones extranjeras que invadían los mercados americanos: «(...) hay que conceder ventajas al costo del papel, sea este importado, sea este fabricado en España, y rebajar al exportar, todo cuanto ha pagado en toda forma de derechos, para que venga muy barato, que esté al alcance de todas las fortunas, y sobre todo con ventajas o al menos en igualdad de condiciones a lo que viene de Francia y Estados Unidos o de Alemania» 25 .

En los mercados americanos el libro español resultaba más caro que el extranjero por el precio y por la forma de pago. El excesivo importe del papel en España, debido a la protección arancelaria que sostenía a la ineficiente industria papelera nacional, encarecían el coste de la producción editorial. Y hasta la generalización del franqueo privilegiado en 1922, las tarifas del transporte también contribuían a elevar el precio del libro. Incluso después de la guerra el libro francés mantuvo un precio competitivo frente al español. Los editores galos utilizaban un tipo de letra más pequeña para utilizar menos papel y para que pesaran menos ${ }^{26}$. El libro español en Argentina se elevó debido al encarecimiento de las materias primas de la postguerra en un 20-25\%, mientras que el francés sufrió un aumento del 80-100\% pero, por la depreciación del franco quedó reducido casi a la cuarta parte. De este modo el libro francés siguió siendo más barato que el español como antes de $1914^{27}$. Otro elemento a tener en cuenta en el precio poco competitivo del libro español era el tamaño reducido de la mayoría de las tiradas. En la producción de un libro, a parte de los costes fijos como el importe de la composición o de la propiedad intelectual, existen otros como el del papel y de la impresión, que se abaratan o encarecen en función del número de ejemplares. La edición corriente española de un libro medio de cinco pesetas resultaba costosa porque no superaba los 3.000 ejemplares, mientras que muchas tiradas francesas o alemanas llegaban a los 100.000 volúmenes, consiguiendo mayores beneficios al reducir el precio final del libro: «Una venta copiosa obliga, naturalmente, a una tirada copiosa también, y en la tirada, y nada más que en la tirada está el secreto del libro barato. Mientras nuestras ediciones no rebasen la cifra de los 3.000 y los 5.000 ejem-

25 Memoria consular de Chile, s/p. AGA, Sección de Asuntos Exteriores, Caja n ${ }^{\circ} 1274$. «Parece ser que el principal obstáculo que se interpone entre los industriales españoles del libro y los mercados de ultramar, consiste en las clases y en los precios del papel en que imprimen. Si nuestros editores pudieran hacer sus libros en las mismas clases de papel en que los imprimen sus colegas de Estados Unidos, Alemania, Inglaterra, etc., la producción editorial española ya contaría con una rebaja indirecta del precio de los libros que produce, pues a igual costo en el papel, resultaría un libro mejor, que aun vendido a igual precio que el que produce hoy impreso en papel inferior, resultaría rebajado por dar en igual precio un producto de superior valor económico», en Memoria consular de Bolivia, capítulo 5, p. 1. AGA, Caja n 1275.

26 Vid. Informe del librero español, Samuel Nuñez López, p. 9. AGA, Sección de Asuntos Exteriores, Caja $n^{\circ} 1273$. Y Memoria consular de Brasil, s/p. AGA, Caja n ${ }^{\circ} 1274$.

27 Vid. BoIX, Emilio: El libro español en Argentina, Madrid, 1920, p. 20. 
plares, como maximum, nuestro libro, no podrá competir con los extranjeros de difusión extraordinariamente superior a la nuestra» ${ }^{28}$.

Asimismo el desfavorable cambio de la moneda por la sobrevaloración de la peseta en el mercado internacional, perjudicaba notablemente la venta de las publicaciones españolas ${ }^{29}$. Por ejemplo con 1 libra peruana el librero nativo compraba 60 francos de libros editados en Francia o 98 liras de italianos, mientras que sólo podía pagar 25,60 pesetas de libros españoles. Esta diferencia también explica que congregaciones religiosas españolas en Perú compraran devocionarios en castellano a la casa Herder de Friburgo porque costaban cuatro soles menos (diez pesetas) que los procedentes de Barcelona y además estaban mejor encuadernados ${ }^{30}$. En Argentina un volumen corriente español costaba entre 2,50 y 3,50 pesos mientras que un libro francés de similares características valía 1,50. En Chile las novelas en rústica impresas en España costaban de 5 a 7,50 pesos; un tomo de Benavente, que en la Península valía tres pesetas, se vendía a 4,50 pesos chilenos. En Colombia una obra de Pereda llegaba a costar 11 pesetas. Y en Paraguay un volumen de 5 pesetas costaba 45 ó 50 pesos $^{31}$. El cambio sólo era favorable respecto a Gran Bretaña y a Estados Unidos. En la Conferencia Nacional de Editores y Libreros de Barcelona de 1917 ya se advirtió de los perjuicios que ocasionaba en los mercados americanos la elevación del precio de la peseta en el cambio internacional. Los editores solicitaron nivelar el cambio de la peseta para salvar la desproporción en relación con las monedas americanas y, así favorecer la exportación del libro espa$\tilde{n ̃ o l}^{32}$. Además los libreros americanos aprovechaban la conversión de las pesetas a las respectivas monedas nacionales para establecer un sobreprecio en relación con el coste del libro nativo, encareciendo aún más las publicaciones españolas. "Los libreros a favor de precios urdidos en torno a las oscilaciones del cambio, los sobrecargan con cantidades arbitrarias sin relación alguna con los precios de origen ${ }^{33}$. De este modo obtenían importantes beneficios ya que se aprovechaban de este recargo y del descuento hecho por los productores españoles. La mano de obra nacional no suponía un encarecimiento del precio final del libro como demuestra el hecho de que en ningún documento de carácter editorial se hiciera referencia al factor trabajo como un obstáculo a la ex-

28 Opinión del editor y Presidente de la Cámara Oficial del Libro de Madrid, Julián MARTINEZ REUS, en Bibliografía General ..., septiembre de 1918, p. 99.

29 Sobre las repercusiones negativas de la sobrevaloración de la peseta en las exportaciones españolas vid. MARTIN ACEÑA, Pablo: La política monetaria en España 1919-1935, Madrid, 1984.

30 Pinilla, Antonio: El libro español en Perú, Lima, 1922, pp. 25 y 26.

31 Calvo Sotelo, L., Memoria sobre ..., pp. 51-53; El libro español ..., pp. 60-62; "Orientaciones convenientes....» en Bibliografía General ..., enero-febrero de 1927, pp. 1 y 2.

32 Conclusiones al Tema II: «Medios conducentes a la facilidad en los envíos de toda la producción editorial y su reembolso", en Conferencia Nacional de Editores ..., p. 77.

33 Memoria consular de Bolivia, capítulo 5, p. 9. AGA, Sección de Asuntos Exteriores, Caja $n^{\circ} 1275$.

Hispania, LXII/3, núm. 212 (2002) 1021-1058 
pansión del libro español, sino más bien todo lo contrario. Los salarios eran más altos en los países competidores y, sobre todo en América, donde los libreros solicitaban las obras encuadernadas porque los trabajadores eran más caros y estaban peor cualificados

\section{LA COMPETENCIA EXTRANJERA Y LAS EDICIONES FRAUDULENTAS}

A principios del siglo XX el comercio de libros con los países hispanoamericanos era la asignatura pendiente de la industria editorial española. El mercado americano estaba dominado por editores franceses especializados en la producción del libro en castellano (originales y traducciones) como las casas Garnier Frères, Vda. Bouret, Librería Ollendorff, Armand Colin, Roger y Chernovitz, Hachette, Louise Michaud ${ }^{34}$, o la Editorial Franco-Iberoamericana. La penetración francesa se había iniciado en el primer tercio del siglo XIX con el libro francés, debido al enorme prestigio que gozaba el idioma y la cultura francesa entre las élites americanas pero, los editores galos conscientes de las enormes posibilidades que ofrecía este mercado de habla hispana tan amplio y sin explotar, optaron por editar en castellano aprovechando la estancia en París de una importante colonia de españoles e hispanoamericanos, residentes o exiliados, dedicados a tareas de traducción: «La fuerza difusora de las editoriales francesas tenía abierto un ancho canal hacia los países de lengua española, singularmente los de América del Sur. De ahí provenían las secciones hispanas de la industria y el lanzamiento del concepto de América Latina, enderezado a reemplazar los de Iberoamérica o Hispanoamerica» ${ }^{35}$.

También acudieron al prometedor mercado americano con ediciones en castellano otras casas editoriales como la alemana Herder, la inglesa Thomas Nelson, o la estadounidense Appleton ante la importante demanda de publicaciones no abastecida por las incipientes industrias editoriales autóctonas, salvo la argentina, y la insuficiente oferta española. Además estas casas extranjeras concurrían en condiciones superiores desplazando a las publicaciones de la $\mathrm{Pe}$ -

34 El editor Manuel Aguilar se inició en el mundo del libro, como director de la sucursal abierta en Argentina por la editorial Michaud, y representante del consorcio librero que esta casa formó con cuatro editoriales francesas para fomentar sus ventas en Hispanoamérica. Vid. AGUILAR, Manuel: Una experiencia editorial, Madrid, 1972, vol. $1^{\circ}$, pp. 444-452. "(...) Michaud editaba obras en castellano supliendo a una vieja carencia de los editores hispanos e intentando competir con las casas francesas editoras de obras en nuestro idioma, que les ofrecía un magnífico mercado en los países de habla hispana», pp. 447. Aguilar entró en la empresa como corrector de pruebas, contratado por el escritor Manuel Ciges Aparicio, que fue el director literario de la sección española de la casa Michaud desde 1911 hasta 1914. Ciges recreó el mundo variopinto y difícil de los emigrados económicos y exiliados políticos, dedicados a la traducción española como única fuente de ingreso en el París de preguerra, en la novela, Circe y el poetapublicada por Mundo Latino en 1926.

3s AGUILAR, Manuel: Una experiencia ..., pp. 446 y 447. 
nínsula. En América resultaba más fácil y más barato conseguir un libro en castellano editado en París o Leipzig que en España. La superioridad de estas editoriales extranjeras respondía al desarrollo que habían alcanzado en esos países las artes gráficas, a la masiva capitalización de la industria editorial, y a las relaciones comerciales basadas en modernas operaciones financieras. Ofrecían pagos más flexibles que las casas españolas, y realizaban una propaganda intensa y efectiva. La industria editorial española tenía serios problemas para explotar las ventajas iniciales que representaban el idioma común, la historia compartida y el peso de la emigración en aquellas naciones respecto a sus competidoras. La comunidad lingüística y espiritual que formaban España y sus antiguas colonias no bastaba por sí sola para lograr beneficios económicos. Por el contrario los países extranjeros interesados en la introducción de sus productos en los mercados americanos, incluidas las publicaciones, comenzaron a aprender castellano y a ocuparse de cuestiones hispanas. Y así lo entendían los propios españoles contemporáneos, como el editor Gustavo Gili en la Conferencia Nacional de Editores y Amigos del en 1917: «Y esta importancia y ese afán con que se lanzan al estudio de nuestro idioma, no responde a sentimientos de admiración por las bellezas de nuestra lengua y de nuestra literatura. Más utilitarios son los móviles que impulsan a los extranjeros a cultivarla: quieren poseer la lengua de Cervantes para tener con ella una herramienta más de trabajo, una llave que les habla las puertas de los veinte Estados americanos que hablan como nosotros y les permita desenvolverse y afianzarse en ellos» ${ }^{36}$.

Asimismo el retraso en la distribución y el precio de libros propició la aparición de ediciones fraudulentas en todo el continente americano, y principalmente en Argentina, Chile, Uruguay y Paraguay, aunque en casi todas aparecían como lugar de edición Montevideo para eludir cualquier acción judicial porque Uruguay no tenía firmado Tratado de propiedad intelectual con ningún país. Estas ediciones anónimas sin pie de imprenta, o con nombres de supuestas editoriales suponían una competencia desleal muy fuerte, y la ruina de editores y escritores al no pagar derechos de autor. Las ediciones piratas respondían a la demanda desatendida y a la desprotección de la propiedad intelectual en Hispanoamérica. Por una parte eran consecuencia de los problemas que acompañaban al comercio de libros, pero al mismo tiempo impedían el desarrollo normal del mismo. El editor de Madrid o de Barcelona enviaba a un librero americano diez, veinte o cien ejemplares de los títulos que publicaba. Por cualquier circunstancia, alguno de aquellos libros corría fortuna y el librero vendía todos los ejemplares. El público continuaba solicitando el libro pero, el librero no se atrevía a pedir una nueva remesa de aquella obra porque pasarían dos meses antes de que lleguase, y puede que entonces el interés por ese libro

\footnotetext{
36 GILI, Gustavo: «Proyecto de creación de una Cámara del Libro Español o Asociación de los Amigos del Libro», en Conferencia Nacional de Editores ..., Barcelona, p. 89.
} 
haya desaparecido. En esta circunstancia aparece la edición clandestina, que realiza un negocio seguro al ofrecer una obra exitosa reclamada por el lector.

«Este problema del libro parásito es un hijo de la falta de comunicaciones rápidas, pues de igual manera que sin producirse se vende en Bolivia, cuando una obra alcanza éxito en una República y se agotan rápidamente los ejemplares venidos en primera remesa, aprovechando los 3 ó 5 meses que tardarán en llegar los nuevos ejemplares pedidos, el defraudador aprovecha la circunstancia y saca a luz rápidamente la edición fraudulenta, haciendo un seguro, pequeño e innoble negocio»37.

El éxito de las primeras ediciones clandestinas - populares, de quiosco y de baja calidad-, y la impunidad generalizada contribuyeron a la extensión y perfeccionamiento de este fenómeno. De hecho lo más grave era el plagio de ediciones originales europeas (españolas), incluyendo obras técnicas, vendidas a los mismos precios y con destino a las librerías. Los primeros ejemplares que mutilaban el texto original e incluso eran malas traducciones dejaron paso a la copia de la versión legítima, aparecida en España de una obra de éxito seguro. Por ejemplo en la Avda. de Mayo de Buenos Aires podía adquirirse en 1925 un ejemplar de la obra El Indiano de Rusiñol a 20 centavos, mientras que la edición auténtica de Renacimiento costaría 2,50 pesos. Obras traducidas como $E l$ difunto Matías Pascal de Pirandello, o El retrato de Dorian Gray de Wilde se vendían a 50 centavos en los puestos callejeros, y en las ediciones españolas valdrían entre 2,50 y 3 pesos. E incluso en Buenos Aires se editó sin permiso la Gramática de la Real Academia de la Lengua Española. Aunque España había firmado con la mayoría de los países iberoamericanos Tratados de propiedad intelectual y literaria desde fines del S. XIX, el desamparo en la práctica era absoluto porque carecían de mecanismos reales que asegurasen el cumplimiento efectivo de los principios establecidos jurídicamente, y tampoco recogían trámites sencillos y rápidos que sancionasen duramente los delitos cometidos contra los derechos de autor y de edición ${ }^{38}$. Pero, el problema de estas ediciones también estaba relacionado con el excesivo precio que tenían los libros españoles en aquellos mercados debido a las razones ya analizadas: importe del papel, tiradas cortas, cambio de moneda, y al sobreprecio de los libreros americanos. La solución para erradicar este fenómeno era abaratar el libro ya que perserguirlas jurídicamente resultaba bastante difícil y poco efectivo.

«El mayor obstáculo con que tropieza actualmente el comercio del libro en América, es el del precio. Son demasiados caros. Se quejan de ello los libreros y el

37 Memoria consular de Bolivia, capítulo 5, p. 12. AGA, Sección de Asuntos Exteriores, Caja $\mathrm{n}^{\circ}$ 1275. Vid. también a BLANCO FOMBONA, Rufino: «El libro español en América» en CAMARA Oficial de BarCelona, Conferencias sobre el libro español, Barcelona, 1922, p. 182.

38 Gill; Gustavo: Bosquejo de la política del libro, Barcelona, 1944, p. 126. 
público. Volúmenes muy pequeños, de diez a doce pliegos cuestan cuatro y cinco pesetas. El mismo libro, editado en Montevideo, en buen papel y en tiradas de mil ejemplares, no cuesta más allá de 1,50 pesetas. De ahí, principalmente, las numerosas ediciones fraudulentas, que acabarán de desterrar del mercado el libro legítimo. La mejor medida para combatir ese infame desvalijamiento, acaso más eficaz aún que los mismos tratados de propiedad que urge concretar, es la del abaratamiento del libro. Las ediciones clandestinas dejarían de ser negocio y cesarían automáticamente»39.

\section{LA INFRAESTRUCTURA DE LA DIFUSIÓN DEL LIBRO ESPAÑOL}

El comercio librero con Hispanoamérica en los primeros años del siglo XX era precario y deficiente por el desconocimiento generalizado sobre las necesidades de aquellos mercados, y por la actitud pasiva y puntual de la mayoría de los exportadores. Muchos editores se conformaban con conceder la «rancia exclusiva» de sus publicaciones a intermediarios comisionistas o a libreros americanos a cambio de la venta segura de un determinado limitado número de ejemplares, cien o mil, desentendiéndose de la propaganda y difusión de los mismos. «(...) abandonada esta vital función de la propaganda a lo que buenamente quieran hacer allí los tres o cuatro libreros que en cada nación acaparan el negocio de importar obras de España» ${ }^{40}$. No explotaban directamente el negocio porque no conocían las características y el funcionamiento de los mercados consumidores, y en consecuencia no sabían o bien no podían afrontar los riesgos y problemas que entrañaba esta empresa.

«El estado actual del comercio de libros entre España y las Naciones Americanas de origen Español, hemos de confesarlo, carece de importancia, estabilidad, y florecimiento que debieran de serle peculiares. (...). La acción de nuestros competidores es mucho más intensa, bastante más práctica y decididamente más enérgica que la nuestra en cuanto al sostenimiento de aquellos mercados se refiere y a los medios que se pone en práctica para colocar sus ediciones» ${ }^{41}$.

El comercio de libros en el interior de la Península se efectuaba a través del servicio de novedades en consignación y el de compras en firme por pedidos directos de los libreros. El servicio de novedades consistía en el envío a cargo del editor de las publicaciones nuevas y en la devolución de las no vendidas a cuenta de los libreros. Pero este sistema resultaba muy problemático en el co-

39 Dominguez, Emilio: «El comercio de libros en Hispanoamérica» en Bibliografía General ..., junio de 1929 , p. 80

40 «El comercio de la librería en América» en Bibliografía ..., agosto de 1906, p. 70.

41 GaLlaCH Y TORRAS, Joaquín: "Medios prácticos para fomentar y activar el comercio de libros en España y entre la Península y las naciones americanas de origen español» en Crónica de la I Asamblea Nacional de Editores y Libreros, Barcelona, 1909, pp. 92. 
mercio de Ultramar por la distancia. Las remesas de novedades no satisfacían las necesidades del mercado, resultaban excesivas si el libro tenía poca aceptación entre el público, y escasas si el libro obtenía éxito. Además la tardanza en los envíos provocaba que los ejemplares solicitados de un libro demandado perdiesen interés al recibirlos. De este modo los libros invendibles se almacenaban en las librerías despertando las iras de los editores que no cobraban por los volúmenes remitidos, o bien eran devueltos con el consiguiente gasto para los libreros. La inseguridad y los problemas que implicaba el sistema de novedades obligaba a la mayoría de libreros a comprar las obras a un precio mayor en las dos o tres librerías más importantes de cada país que controlaban el negocio $^{42}$. Por esta razón la mayoría de las ventas en América se realizaban en firme, es decir, la compra de libros se realizaba sin posibilidad de devolución, previa petición. Pero la singularidad de la mercancía-libro no permitía al librero la adquisición de partidas importantes, salvo de libros de venta segura como los de texto o clásicos de la literatura, por los riesgos que acarreaba. Por otra parte la inexistencia de catálogos y/o boletines bibliográficos completos y actualizados impedían la petición anticipada. El librero americano recibía los paquetes de libros ignorando su contenido, confiado en el criterio del editor español: «Hace veinte años, aún pedían libros aquellos libreros sin detallar títulos. - Manden tres cajones de libros - escribían»" «-Mándenos usted quince mil pesetas de novelas-. Y allá van quince mil pesetas de novelas. Otras veces nos hacen el pedido por kilos: - Apunte tantos kilos de obras entretenidas${ }^{44}$. Estas prácticas generalizas entre los libreros americanos estaban relacionadas con la nula propaganda de librería realizada por los editores españoles sobre su propia producción bibliográfica. Difícilmente se va hacer el pedido de un libro si se desconoce su existencia. En este sentido cabe destacar que el primer catálogo bibliográfico del conjunto de la producción española apareció, muy tardíamente, entre los años 1932 y 1936 en tres tomos. El Catálogo General de la Librería Española e Hispanoamericana, publicado por las Cámaras Oficiales del Libro de Madrid y Barcelona con subvención estatal, recogía en más de 50.000 fichas por autores los libros aparecidos en España e Hispanoamérica entre 1900 y 1930 . Este repertorio bibliográfico era un instrumento necesario para la expansión del libro y así había sido reclamado desde principios de siglo, pero no tomó cuerpo hasta la Conferencia Nacional del Libro de 1927. Mientras se «preparaba» el catálogo general la única información bibliográfica global fue recogida en las páginas del Boletín de la propia Asociación, Bibliografía Española, de carácter profesional. El epígrafe «Bibliografía» reunía las nuevas

42 Vid. Venegas, José: Los problemas del libro en lengua castellana, Madrid, 1931, pp. 92 y 93.

43 Charla de Manuel Aguilar en la Escuela de Librería en 1932, recogida en Bibliografía General ..., Madrid, de 1932, p. 157.

44 Comentario hecho por Joaquín de Oteyza, representante depositario de la casa editorial Sopena, a un periódico mexicano en 1926. En MANGADA, Antonio y POL, Jesús: Libreros y editores (1920-1960). Joaquín de Oteyza: Biografía de un empresario del libro, Madrid, 1996, p. 87.

Hispania, LXII/3, núm. 212 (2002) 1021-1058 
publicaciones mes a mes, clasificadas por materias y autores, y precedida de un índice general por orden alfabético de los autores, colaboradores y traductores incluidos. Asimismo destacaba la función propagandística y difusora del apartado de «Anunciantes».

«(...) he recogido en todas partes, con el más vivo y renovado deseo de conocer ampliamente nuestra moderna producción científica de todos los órdenes, la queja en punto a la obtención fácil y económica de libros españoles. La mayoría de nuestros editores descuidan el mercado de América, limitándose a servir (con el retraso consiguiente), por medio de sus corresponsales, los pedidos que se les hacen; en vez de provocar esos pedidos y el conocimiento de sus publicaciones mediante el envío constante de ellas, su manifestación en los escaparates de las librerías y el anuncio. De aquí que muchos de los profesores y aficionados que buscan nuestros libros (cuando por casualidad saben de ellos), encuentren más cómodo encargarlos directamente a Francia o Alemania, con gran daño de nuestro de comercio de librería, y a la postre, de la difusión de los escritores» ${ }^{45}$.

A parte del catálogo general, también era indispensable la distribución regular por parte de cada editorial de boletines e índices mensuales que recogiesen las publicaciones disponibles así como las novedades, repartidos en librerías, centros de educación y cultura, e incluso a particulares interesados. Pero, las casas españolas no enviaban completa información bibliográfica a sus clientes americanos, salvo excepciones como Calleja y CALPE: «(...) la conocidísima y acreditada casa editora Calleja, que debe precisamente el éxito colosal de sus negocios en América, a la propaganda amplia e interesantísima que hace de sus obras» ${ }^{46}$. «De casas españolas a excepción de la editorial CALPE de la que he visto catálogos y el Boletín de la Cooperación voluntaria de Amigos del Libro, apenas si dentro de algún volumen se encuentra una hojita, señalando los últimos tomos publicados por la casa que ha editado el libro que la contiene. A esto se reduce toda la propaganda $\gg^{47}$. En las memorias consulares se insistía en la intensificación de la propaganda y se reclamaba como medio eficaz de difusión a parte del catálogo o de la circular, a imitación de franceses y norteamericanos, el envío a los corresponsales de un ejemplar por cada obra nueva, gratis, con derecho a devolución, o bien a un precio reducido ${ }^{48}$. La débil propaganda española contrastaba enormemente con la intensa labor difusora francesa y alemana, que incluso anunciaban sus novedades en la revista, Bibliografía Espa-

45 Altamira, Rafael: Mi viaje a América, Madrid, 1911, pp. 76 y 77.

46 ZARATE, Rodrigo de: España y América, Madrid, 1917, p. 314.

47 Memoria consular de Bolivia, capítulo 9, p. 1. AGA, Sección de Asuntos Exteriores, Caja no 1275. «(...) tengo que hacer una excepción de la «Editorial Española Calpe», la cual trabaja a satisfacción de libreros y lectores, manda catálogos a centenares, que están a la mano de todos en las librerías», en Pinilla, Antonio: El libro español ..., pp. 43 y 44.

48 Vid. Memoria consular de Cienfuegos (Cuba), pp. 7 y 8. AGA, Sección de Asuntos Exteriores, Caja $\mathrm{n}^{\circ} 1274$.

Hispania, LXII/3, núm. 212 (2002) 1021-1058 
ñola, para introducirse en España, pero sobre todo en el mercado americano, ya que muchos libreros de aquel continente estaban suscritos a esta revista profesional y bibliográfica. Aunque se intensificó la propaganda del libro español a lo largo de este período se siguieron utilizando los medios normales como catálogos, boletines, hojas sueltas, y reseñas bibliográficas en prensa. Pero, los nuevos sistemas de publicidad de los años 20 y 30 como el anuncio en tranvías, pantallas de cine ... etc. no eran utilizadas en América sino en España, salvo los casos de Espasa-Calpe y la CIAP, que establecieron depósitos de sus publicaciones en las principales capitales americanas, y explotaron las posibilidades del libro como una mercancía más. La falta de conocimientos sobre la situación de los mercados americanos y la escasa difusión de la producción bibliográfica española hicieron indispensable la figura del viajante del libro, como agente de información comercial de librería para estudiar las características del negocio y establecer vínculos con el mayor número de clientes. Las casas españolas debían familiarizarse con las costumbres y sistema de ventas, así como asegurarse de la solvencia y del crédito de las librerías. Estos representantes debían establecer redes comerciales en los distintos países hispanoamericanos y promocionar las publicaciones de las editoriales que defendían. El editor Ruiz Castillo, fundador de Biblioteca Nueva en 1917, fue uno de los primeros que cruzó el Atlántico como director comercial de Renacimiento para introducirse en los mercados de Argentina y Chile entre 1912 y 1914 . En su primer viaje difundió las obras de Ricardo León y Pío Baroja, desconocidos para el público chileno, logrando vender en un sólo día libros por 40.000 pesetas ${ }^{49}$. Anteriormente casas como Hernando ${ }^{50}$ y Calleja habían enviado corresponsales a Iberoamérica, conscientes de la importancia de negociar directamente con los libreros y mayoristas americanos, pero no era una práctica muy extendida entre las editoriales españolas como reflejan las memorias consulares de 1922. En ellas se reclamaban la presencia de agentes de comercio eficaces y competentes:

«Es muy deficiente el sistema de venta del libro español. La casa Calleja puede decirse que ha sido la única que ha querido trabajarlo; pero sus visitas a la América, al menos en estos mares, son tardías y el alejamiento de sus vendedores da facilidades a los que llegan a cada momento en busca de compradores. Acaba de pasar por Chile el representante de dicha casa y me asegura que sus viaje le abrió nuevamente el mercado, pues había vendido ya más de 150.000 pesetas, y aún no había terminado su trabajo»51.

49 Ruiz-CaStillo BASAla, José: Memorias de un editor. El apasionante mundo del libro, Madrid, 1986, p. 86. «El comercio de librería», charla del Ruiz Castillo en la Escuela de Librería, en Bibliografía General ..., octubre de 1932, pp. 139 y 140.

so Sobre la política comercial de Hernando en el mercado americano vid. BOTREL, JeanFrançois: «Nacimiento y auge de una editorial escolar: Casa Hernando de Madrid (1828-1902)» en Libros, prensa y lectura en la España del S. XIX, Madrid, 1993, p. 432-435.

${ }_{51}$ Memoria consular de Chile, s/p., AGA, Sección de Asuntos Exteriores, Caja n ${ }^{\circ} 1274$. 
De este modo los viajantes emprendieron la aventura del libro español en América como Joaquín de Oteyza en 1926, representante depositario de la editorial Sopena de Barcelona, para difundir las publicaciones de los fondos editoriales que representaban y gestionar las ventas de las mismas. En su segundo viaje en 1928 partió a Buenos Aires con la representación de quince casas españolas y una francesa: Editorial Pueyo, Salvat Editores, S. A., Gustavo Gili, Ruiz Hnos., Sociedad General Española de Librería, Compañía IberoAmericana de Publicaciones, Editorial Voluntad, Editorial Juventud, Roberto de San Martín, Reus, Librería Editorial Dossat, Mundo Latino, Editorial Seguí, Estampa, Librería Editorial Hernando, y la Casa Editorial Franco IberoAmericana de París.

La tardanza excesiva de los envíos ( 2 meses), ya fuese por vía postal o por aduana, y el precio de los mismos dificultaba el crecimiento y continuidad de las relaciones mercantiles con aquellos mercados. Estos obstáculos estaban relacionados con las deficiencias de las comunicaciones españolas, que necesitaba de servicios marítimos y terrestres extranjeros complementarios para transportar las mercancías, encareciendo el coste de los portes. En la Asamblea de Barcelona de 1909, el editor E. Bailly-Baillière se quejaba del excesivo importe de los paquetes postales enviados a América a través de Francia e Inglaterra. Los paquetes remitidos a Méjico costaban 4,50 francos, y desde Francia sólo 3 francos, ya que tenían que abonar 0,75 pesetas a los servicios franceses y 1 peseta a los ingleses ${ }^{52}$. En este sentido el I Congreso Nacional del Comercio en Ultramar de 1923 puso de manifiesto la necesidad de mejorar y ampliar las comunicaciones marítimas directas, así como los servicios postales por la importancia que tenía para el desarrollo del comercio español ${ }^{33}$. El servicio internacional de paquetes postales fue creado por la Unión Universal de Correos en la Conferencia de París en 1880, y quedó establecido en España en 1886. Pero, el primer intercambio directo de paquetes con un país americano no tuvo lugar hasta 1915 , debido a las deficiencias de medios y personal de Correos, y al servicio insuficiente que ofrecían las compañías de ferrocarriles nacionales, lo que obligaba a la Administración española a utilizar medios de transporte extranjeros para los envíos propios. El 1 de febrero de ese año se estableció el cambio directo de paquetes con Uruguay, el 10 de octubre con Argentina, y a través de los servicios argentinos se extendía a Bolivia, Perú, Paraguay y Chile, a falta de

s2 Crónica de la I Asamblea ..., pp. 133-134. Ya en 1857 el librero catalán con establecimiento en Madrid, Gaspar Roig, ofrecía los libros de su fondo en un anuncio de la revista La América, pero indicaba que debido a las dificultades de comercialización, lo pedidos debían realizarse a través de Jules Hue y Cía. de Burdeos. Vid. RAMA, Carlos: Historia de las ..., p. 248.

53 Vid. "Comunicaciones y servicios postales», Sección $3^{\mathrm{a}}$, Fascículo $\mathrm{n}^{\circ} 1$ en Primer Congreso Nacional del..., pp. 18, 30 y 31. AGA, Sección de Asuntos Exteriores, Caja n ${ }^{\circ} 5416$. Y el apartado $\mathrm{XX}$ de las conclusiones sobre comunicaciones y servicios postales, en I Congreso Nacional del Comercio Español en Ultramar, Madrid, 1923, pp. 33-35.

Hispania, LXII/3, núm. 212 (2002) 1021-1058 
una línea de navegación directa con.los puertos del Pacífico ${ }^{54}$. El servicio postal entre España y América, controlado por los vapores-correo de la Compañía Transatlántica, era el más utilizado en la exportación librera debido a las características de la mercancía, y a las ventajas que ofrecía frente al transporte por aduana. La mayoría de los pedidos se enviaban en varios paquetes postales ya que las tarifas de franqueo eran más baratas que los fletes y llegaban más «rápido» por la regularidad del servicio: «Nadie ignora que la casi totalidad de las remesas se efectúa en paquetes postales; en cajas van los volúmenes que no pueden remitirse, sin riesgo de deterioro o por sobrepasar el peso autorizado, en paquetes postales» ${ }^{55}$. Además los servicios de Correos resultaban fundamentales en el comercio librero porque no sólo se utilizaban para enviar la mercancía a provincias y a Ultramar, sino también para mandar toda la correspondencia que generaba el negocio como las tarjetas de pedido, avisos de recibo, los boletines y catálogos de información bibliográfica, o los prospectos de propaganda, y al mismo tiempo servía de medio de pago a través de los giros postales. En este sentido destacan las numerosas y recurrentes peticiones de los editores dirigidas a la Dirección General de Correos para mejorar las condiciones y rebajar el franqueo de los servicios postales, debido a su utilización masiva.

«Para cualquier país de América un paquete conteniendo libros paga pesetas 2,25 en su máximo peso, los ya citados dos kilos, que suelen satisfacerse con cinco ejemplares de libro corriente, con precio fijado a pesetas 3. Resulta en este caso que cada ejemplar tiene un sobrecargo de 45 céntimos, ó sea el 15 por ciento de la venta, no ya del costo» 56 .

Los editores reivindicaron tarifas de franqueo más económicas por la gran cantidad de envíos realizados, el establecimiento del servicio de paquetes contra reembolso con Iberoamérica para asegurarse el cobro de los libros, así como el aumento del peso máximo de los paquetes de varios libros hasta 3 kilos e ilimitado para aquellos que contuviesen un sólo volumen, ya que algunos libros especiales como tomos de diccionarios o enciclopedias sobrepasaban el límite aceptado entonces de 2 kilos y tenían que ser enviados sin encuadernar en distintos paquetes. Igualmente solicitaron la creación de tarifas especiales de un cuarto de céntimo o de medio céntimo de peseta por cada 10 gramos de peso para los impresos de propaganda y servicio de librería ${ }^{57}$. Algunas de estas demandas relacionadas con el funcionamiento de Correos se vieron satisfechas con

54 El 1 de febrero de 1916 se firmó con Costa Rica y Panamá; el 1 de julio con Colombia; el 1 de octubre con El Salvador; el 20 de enero de 1917 con Ecuador; el 1 de enero de 1918 con Venezuela; el 1 de septiembre de 1919 con los Estados Unidos; el 1 de marzo de 1920 con Méjico; y el 15 de febrero de 1923 con la República Dominicana.

s5 VENEGAS, José: El problema del libro ..., p. 97.

56 «Por el libro español» en Bibliografía ..., septiembre de 1913, p. 66.

57 Crónica de la I Asamblea..., pp. 102-103 y 110-111. 
la firma en Madrid del Convenio Postal Hispano-Americano el 13 de noviembre de 1920, y puesto en vigor por Real Decreto del Ministerio de Gobernación el 7 de enero de 1922. En virtud del mismo España, toda América, y el Archipiélago de Filipinas quedaron constituidos en un sólo territorio postal, con régimen de tránsito gratuito y franqueo igual al interior de cada uno de los países interesados para la circulación de correspondencia, impresos y muestras comerciales $^{58}$. Gracias a este acuerdo y a la adhesión de España a la Unión Postal Panamericana de $1921^{59}$, se estableció un sistema especial y reducido de tarifas postales hispanoamericanas tan vehementemente solicitado desde principios de siglo por la mayoría de los comerciantes. Destacó especialmente el establecimiento del franqueo privilegiado de 25 céntimos por kilo en los envíos a América, y el aumento del peso límite de los paquetes postales a 5 kilos. La rebaja en el franqueo fue considerable ya que hasta entonces se pagaba una peseta por kilo en los envíos a América, encareciendo demasiado el precio de venta de los libros. Así por ejemplo el famoso Tratado de Paz de Versalles, costaba 6 reales pero, como pesaba 265 gramos con los mapas, tenía que pagar 26 céntimos de franqueo y 25 por certificado. En 1921 el envío de dos kilos de libros costaba 2,25 pesetas, y en 1922 los mismos dos kilos costaban 0,55 pe$\operatorname{setas}^{60}$. Este franqueo constituía una ventaja considerable para la industria española respecto a los demás países europeos, pero también fue aprovechada por los editores franceses, quienes introducían sus libros en España a través de la Sociedad General Española de Librería, gran distribuidora de publicaciones en España y América filial de la casa Hachette, y concesionaria de los quioscos de las estaciones de ferrocarriles españoles ${ }^{61}$. Después los paquetes de libros franceses eran reexportados a los mercados americanos por vía postal como si fuesen españoles, beneficiándose de esta tarifa de franqueo tan favorable, ya que mandar un kilo de libros desde Francia costaban 4 francos. Esta práctica francesa, que siglos atrás había sido utilizada para burlar el monopolio comercial de la Península con las Indias, fue denunciada por el Comité Oficial del Libro y

58 Vid. el texto y las ratificaciones del Convenio Postal Hispano-Americano en el estudio realizado por el oficial de Correos, CAlvo HeRnÁNDEZ, Benigno: El servicio de Correos entre España y América, Barcelona, 1922, pp. 9-13. Este obra, editada por la Cámara Oficial del Libro de Barcelona, resultaba de gran utilidad para las casas editoriales exportadoras ya que recogía los itinerarios, fechas, horarios y tarifas de los correos marítimos.

59 Este acuerdo panamericano, a diferencia del Convenio Hispano-Americano, dejaba libertad a cada país para fijar una tarifa de franqueo panamericano, siempre que no sean superiores a la mitad del máximo fijado por la UPU en dólares. Vid. FLOREZ NIN, Rafael: «La Unión Postal Panamericana. Ingreso de España en la misma» en Mercurio, Barcelona, n 460, 3 de abril de 1924, pp. 119 y 120.

60 Memoria de la Cámara Oficial del Libro de Barcelona correspondiente al ejercicio 1922, p. 20.

$61 \mathrm{La}$ introducción de publicaciones francesas en España con destino a los mercados americanos resultaba fácil a través de la Sociedad General Española de Librería ya que tenía la exclusiva de venta de las ediciones españolas de la casa Hachette, de la editorial Ollendorff y del escritor Anatole France entre otros. 
por los cónsules españoles en sus informes de 1922 ya que reducía la ventaja de los exportadores españoles respecto al principal competidor en aquellos mercados. El director de este organismo, José Estrada, dirigió una carta al $\mathbf{M}^{\circ}$ de Estado el 22 de julio de 1922 exponiendo que el disfrute abusivo del franqueo privilegiado por parte de las casas editoriales francesas vulneraba las condiciones del Convenio Postal Hispanoamericano, y perjudicaba los intereses del comercio librero español. Pero, como la expedición de libros franceses a España era lícita el Ministerio contestó que no podía tomar ninguna medida restrictiva, y que correspondía al $\mathrm{M}^{\circ}$ de Gobernación y a la Dirección General de Correos vigilar el estricto cumplimiento de este acuerdo postal, aunque como esta empresa estaba establecida en el país resultaba difícil impedir que utilizara normalmente los servicios postales nacionales y más cuando también enviaba libros españoles ${ }^{62}$. La regularidad y celeridad de los transportes ya fuesen nacionales o extranjeros resultaba fundamental para abastecer el mercado y evitar la aparición de las ediciones piratas, que lesionaban los intereses de autores y editoriales legales. De hecho las Cámaras Oficiales del Libro instaron a la Dirección de Correos a utilizar vapores extranjeros, y en especial las compañías italianas que hacían escala Barcelona, para evitar el retraso en los pedidos destinados a América. La tardanza en los pedidos, sobre todo de segundas remesas también podía provocar que los libros dejasen de interesar y los clientes no los comprasen porque ya no era novedad, o bien porque ya lo habían adquirido en otras librerías. Otra cuestión relacionada con los envíos de libros a América era el embalaje y acondicionamiento de los mismos. Muchos editores descuidaban este aspecto ignorando la larga travesía que sufrían los libros desde su salida del almacén hasta su colocación en el estante del librero de Buenos Aires o Lima. Las publicaciones remitidas por vía postal necesitaban un empaque sólido para protegerlas de los golpes y de la humedad, y evitar así que llegasen sucias y con los bordes achatados. Los libros por Aduana al ser enviados en cajas estaban más y mejor protegidos. De hecho las obras de valor y de colección eran mandadas por carga.

La estricta forma de pago exigida a los libreros americanos, debido a las limitaciones económicas de la mayoría de las editoriales y a la débil estructura financiera española, impedía la colocación de los libros en aquellos países. La mayoría de los libreros americanos con escaso capital necesitaban largos plazos para liquidar la mercancía recibida y saldar sus cuentas con las casas suministradoras, ya que la venta del libro al público no era inmediata. Además como el tipo de cambio respecto a la peseta les era desfavorable, pero sufría fuertes oscilaciones, solían esperar a un cambio más propicio para pagar sus deudas. Los

62 Correspondencia entre el Comité Oficial del Libro y el Ministerio de Estado. AGA, Sección de Asuntos Exteriores, Caja n ${ }^{\circ} 1274$. Informe del librero español Samuel Nuñez López, establecido en Río de Janeiro desde 1909 en respuesta al cuestionario sobre la situación del libro español, p. 8, Caja $n^{\circ}$ 1273. Memoria consular de Brasil, s/p., Caja $n^{\circ} 1274$. Vid. también la Memoria de la Cámara Oficial del Libro de Barcelona ..., 1922, p. 47. 
negocios en América se realizaban con el crédito llevado al extremo. Aunque las formas de pago eran diversas, las memorias consulares destacaban que las casas extranjeras ofrecían mayores facilidades y plazos más flexibles en los pagos, incluso después de la guerra mundial. El plazo ordinario de los editores españoles en los cobros era de 30 ó 60 días después de la llegada de los libros, aunque a veces los libreros recibían la letra antes que el pedido debido a la tardanza de los envíos. Otros exigían el $60 \%$ al contado, lo que suponía anticipar el pago ya que el libro era un producto de salida lenta, e incluso algunos solicitaban el $50 \%$ del total antes de la llegada de la mercancía. «(...) poco han hecho las casas editoras españolas para afianzar su conquista mercantil del libro, ya que sus 30 días fecha o al contado violento pugna con la forma fijada por los otros vendedores» ${ }^{63}$. La mayoría de editoriales francesas tenían abiertas cuentas corrientes con los clientes americanos que se liquidaban a voluntad del librero en un plazo de tres meses a seis meses e incluso a lo largo del año, o bien dividían la cantidad a pagar en tres letras a 30,60 y 90 días vista, pero en cualquier caso nunca giraban la letra hasta 60 ó 90 días después de haber remitido la mercancía y solían esperar las ordenes del librero. Otros exportadores que no tenían cuentas abiertas recibían giros postales directos de los mismos libreros o de las casas comisionistas también a tres o seis meses. Además franceses y estadounidenses regalaban un ejemplar por cada docena de libros comprados, y si la factura se pagaba antes de 90 días desde de la aceptación hacían un descuento del $10 \%$ sobre el total porque consideraban que el pago se hacía al contado. Y aceptaban la devolución de ejemplares no vendidos. Las editoriales españolas no podían ofrecer estas ventajosas condiciones debido a la descapitalización de la industria del libro y, a la falta de entidades financieras que concediesen crédito al comercio exterior para cubrir las necesidades de los productores y facilitar el pago a largo plazo de los consumidores como ocurría con las casas alemanas. Los exportadores españoles que ofrecían mejores requisitos similares a los extrajeras eran las empresas más modernas. Además la banca española no descontaba letras americanas como se hacía en Londres o París.

«Para que el comercio español de libros pueda hacer competencia al extranjero y al mismo tiempo evitar la inmovilización momentánea de su capital o los efectos de esa inmovilización, no hay más que dos recursos: acudir a bancos para hacer operaciones de descuento que permitan convertir en capital circulante, aunque algo reducido, el capital ya industrializado, pero no reembolsado; o constituir asociaciones con garantías suficientes para realizar una operación de crédito que permita disponer de fondos en cantidad bastante para producir y poder esperar los plazos de cobro» ${ }^{64}$.

63 Memoria consular de Ecuador, p. 2. AGA, Sección de Asuntos Exteriores, Caja $\mathrm{n}^{\circ} 1274$.

64 «El comercio de librería y el crédito» en Bibliografía ..., noviembre de 1912, p. 86. 
Era necesario un organismo crediticio que favoreciese la exportación estableciendo agencias en las principales plazas compradoras de América, que después de informarse sobre el crédito y la responsabilidad de los importadores, adelantase el dinero a los exportadores una vez recibidos los giros aceptados o las notas de vencimiento sobre los pedidos. En este sentido en el I Congreso Nacional del Comercio de Ultramar de 1923 se exigió que el Banco de Crédito Industrial fuese transformado para fomentar el crédito al comercio exterior. Y en la Conferencia Nacional del Libro de 1927 se recomendaba plazos de venta no inferiores a los seis meses, ya que a mayor liberalidad se conseguía mayor demanda. También se insistió en la necesidad de crear un banco de exportación o al menos que el Banco de España siguiendo el ejemplo del Deutsche Bank concediese largos plazos a los libreros americanos, y al mismo tiempo facilitase inmediatamente el importe del pago a los editores españoles para continuar con las tareas editoras ${ }^{65}$. Así en 1928 se creó el Banco Exterior de España para responder a las necesidades del comercio nacional, aunque no resolvió el grave problema del crédito. Para facilitar el cobro de los envíos en la Conferencia del Libro, así como en el II Congreso del Comercio Español en Ultramar se solicitó la creación de una letra de cambio para uso exclusivo de editores, libreros y empresas periodísticas, valederas para giros no superiores a 250 pesetas y con un timbre único de 15 céntimos. La mayoría de los editores españoles de escaso capital siempre se quejaron del excesivo retraso en los cobros de los envíos a América, ya que necesitaban conseguir los beneficios de la venta libros para continuar con sus negocios. Asimismo se lamentaban de los innumerables pedidos incobrables. Pero este grave problema respondía a la desinformación comercial sobre la solvencia de los clientes y a la falta de rigor de muchos agentes que con tal de hacer notas de pedidos no se preocupaban de estudiar las posibilidades económicas de las librerías. La demora en los pagos y los créditos incobrables generaban recelo en los editores españoles hacia los libreros de allá. El exceso de confianza en los envíos contrastaba con las rígidas condiciones exigidas en el pago, que provocaban el resentimiento cuando no el rechazo de los clientes americanos hacia el modo de operar de las casas españolas. Además en los informes consulares se denunciaba la colocación de libros antiguos invendibles en el mercado americano, presentados como publicaciones recientes con un precio superior, acorde con la novedad. Esta práctica demasiado generalizada no beneficiaba los intereses y prestigio del comercio español. El problema de los cobros americanos se agravó después de la crisis económica del 29 debido a las restricciones impuestas en aquellos países a la salida de numerario, incluso aún para pagar facturas. Esta situación agravó la marcha económica de las casas exportadoras españolas.

65 Sobre las carencias de la organización comercial española, y la necesidad de crear un Banco de Exportación Comercial, vid. ZARATE, Rodrigo de, España y ..., pp. 205-228.

Hispania, LXII/3, núm. 212 (2002) 1021-1058 


\section{EL CONSUMO DE LIBROS EN LOS MERCADOS AMERICANOS}

No resulta posible cuantificar el volumen de la exportación de libros a América, ni valorar los beneficios que reportaron a la industria editorial. La información de la Dirección General de Aduanas es muy insuficiente porque sólo recoge los libros exportados en cajas por embarque, y prescinde de los enviados en paquete postal ordinario o certificado, que representaban el grueso de la exportación ${ }^{66}$. El servicio de Correos a pesar de sus deficiencias resultaba más barato y más rápido que las expediciones en cajas, sobre todo a partir del establecimiento del franqueo privilegiado en 1922. De hecho a partir de esa fecha en las estadísticas de Aduanas se aprecia un descenso muy considerable en kilos de libros enviados por embarque, respecto a los años anteriores. En un escrito de la Asociación de Libreros de México de 1935 afirmaban: «(...) el costo de envío como ya antes se dijo es por la vía postal, pues a pesar de lo relativamente caro es más barato que por carga en barco español, y sobre todo infinitamente más rápido y desprovisto de las muchas molestias que originan los envíos por carga ${ }^{67}$. Y las estadísticas de la Dirección General de Correos tampoco nos ayudan porque únicamente ofrecen datos globales del movimiento de paquetes postales, sin especificar el contenido de los mismos, ya que no están desglosados por grupos de mercancías, ni por tarifas de franqueo. Para concretar los datos aduaneros también se gestionó de la Dirección General de Aduanas el desglose de las cantidades y valores de los libros exportados, separándolos del conjunto de impresos, y así se estableció por R. O. del Ministerio de Hacienda del 26 de abril de 1922. «Desgraciadamente, las estadísticas exactas faltan, por cuanto el grueso de nuestras exportaciones se ha efectuado siempre en gran parte por vía postal, y las aduanas registran únicamente los envíos efectuados en cajas, que sólo representan, como queda dicho, una mínima parte de las exportaciones» ${ }^{68}$. Este desconocimiento del volumen de libros exportados explica las desiguales valoraciones acerca de los ingresos que reportaron a la economía nacional. Así la Cámara Oficial del Libro de Barcelona desestimó la cifra anual media de 4.000 .000 millones de pesetas, que arrojaban las estadísticas de Aduanas para la exportación del quinquenio 1915-1919 (entre los

66 Botrel en su estudio pionero sobre el comercio de libros e impresos entre España y Francia también utilizó las estadíticas de aduanas, a pesar de las limitaciones de la fuente al no recoger la exportación postal de libros. Además destacaba la heterogeneidad de los datos, y la variación de los capítulos donde se incluían los libros e impresos a lo largo de los años. Vid. a BOTREL, JeanFrançois: «Le commerce des livres et imprimés entre l'Espagne et la France (1850-1920)» en España, Francia y la Comunidad Europea (Actas del Il Coloquio hispano francés de 1986), Madrid, 1989, pp. 115-133. Y «El comercio de los libros y de los impresos entre España y Francia (1850-1920)» en Libros, prensa ..., pp. 578-601.

67 Exposición enviada por la Asociación de Libreros de México al también librero español, León Sánchez Cuesta, el 8 de junio de 1935, p. 6.

68 GILI, Gustavo: Bosquejo de una ..., p. 88.

Hispania, LXII/3, núm. 212 (2002) 1021-1058 
3.798.444 de pesetas de 1916, la cifra más baja, y los 6.447.315 de 1918, el año que más se vendió), porque esos datos prescindían de los miles y miles de paquetes que se enviaban por Correo. En cualquier caso en este período en las estadísticas de Aduanas se aprecia un importante aumento de los libros enviados a aquellos países por el desabastecimiento de los competidores beligerantes, e igualmente debió aumentar la exportación por vía postal. La importancia de los servicios postales en el comercio librero explica que una editorial en 1921 mandase 7.189 paquetes postales con un peso total de 14.000 kilos y por valor de 160.580 pesetas, y 89 cajas por Aduanas con 10.164 kilos de libros por valor de 116.623 ptas. Y otra casa había exportado casi el $50 \%$ de sus libros por correo y en el primer semestre de 1921 los dos tercios de la exportación a Perú se había hecho en paquete postal, no registrándose en las estadísticas del comercio exterior. La editorial Renacimiento en los años anteriores a la guerra mundial gastaba anualmente 400.000 pesetas en franqueo para España y sobre todo para América. Asimismo la Cámara consideraba que existía un error en la valoración de las estadísticas aduaneras porque evaluaban los libros a 3 pesetas kilo, cuando su valor no era inferior a 5 pesetas.

La entidad barcelonesa estimaba que el conjunto de la exportación a América excedía el $50 \%$ de la producción editorial. Y consideraba que la exportación anual de libros suponía unos 28.000 .000 de pesetas de beneficios para la industria editorial frente a la media aproximada de 4.000 .000 que recogía Aduanas. Se basaba en las siguientes cuentas:

- Número anual de obras nuevas que se publicaban 4.000

- Promedio de ejemplares de cada tirada 3.000

- Promedio total de ejemplares 12.000 .000

- Valor de 12.000.000 ejemplares de libros, a 5 pesetas Ptas. 60.000 .000

- Valor de las nuevas ediciones o reimpresiones Ptas. 20.000.000

- Total Ptas. 80.000.000

- Descuento medio de librería (30\%) Ptas. 24.000.000

- Valor neto Ptas. 56.000 .000

- Exportación mínima (50\%) Ptas. 28.000.000

Quizás 28 millones fuera una cantidad excesiva pero, las cifras reales se aproximaban más a los cálculos de la Cámara que a los datos de Aduanas. En 1925 el Consejo Nacional de Economía atribuía en su estadística un valor de 1.068 .000 pesetas en concepto de la exportación librera, pero nuevamente la Cámara del Libro calculaba que la exportación suma de 20.000.000 a 25.000 .000 de pesetas, a pesar del receso económico de la postguerra y de la reducción de las exportaciones españolas por la reaparición de los contendientes en los mercados americanos. En 1932 se valoraba que la exportación librera aportaba 32.000.000 de pesetas a la economía nacional. El editor catalán Gustavo Gili afirmaba que en 1921 su casa exportaba a los países hispanos el 52\% de sus ventas. Y calculaba que antes de la guerra civil la industria editorial española 
exportaba algo más del $39 \%$ de lo vendido en un año, y siguiendo los datos de la Cámara del Libro exponía que el $70 \%$ de la cifra total de exportación correspondía a la zona de Barcelona y el 30\% a la de Madrid. En España la industria editorial catalana se había ocupado más del prometedor mercado americano por una mayor inclinación económica americanista y por la proximidad del Puerto de Barcelona. De hecho casas como Salvat, Sopena, Montaner y Simón o Maucci se especializaron en diccionarios, enciclopedias, manuales técnicos y científicos, así como en novelas de autores extranjeros muy conocidos para atender la gran demanda que este tipo de obras tenía en los países iberoamericanos. Incluso, algunas editoriales instaladas en Barcelona se centraron en la producción del libro hispánico, distribuyendo casi la totalidad de sus ediciones en América, y despreocupándose del mercado interior, más abastecido por los editores madrileños. El escritor y director de la editorial América, Rufino Blanco Fombona, en el ciclo de conferencias sobre el libro español desarrolladas en Barcelona en 1922, expuso que el comercio de libros con América dejaba anualmente de 8.000 .000 a 10.000 .000 de pesetas. El italiano Maucci establecido en Barcelona en 1892 como librero de viejo, llegó a crear una casa editorial que exportaba los dos tercios de las tiradas de sus publicaciones a las sucursales que dirigían sus hermanos en Méjico y Buenos Aires. Sobre todo novelas de Tolstoi, Gorki, Dostoiewski, Víctor Hugo, Flaubert y Zola ${ }^{69}$. La editorial Sempere de Valencia desde 1901 enviaba más de la mitad de su producción a Hispanoamérica. De títulos como La conquista del pan de Kropotkin con seis ediciones entre 1900 y 1909 vendió 28.000 ejemplares en España y 22.000 en América. De El Capital de Karl Marx distribuyó 9.000 volúmenes en el país y 14.000 en los países hispanos. De la obra El origen del hombre de Darwin se vendieron 22.000 libros en la Península y 29.000 en Iberoamérica. Y de $A s i ́$ hablaba Zaratrusta de Nietzsche fueron destinados 5.000 ejemplares para consumo interno y 7.000 para el mercado americano ${ }^{70}$. Sobre la importancia y dimensión de la exportación a América destacan los ingresos de la editorial Sopena, que en 1926 gracias al primer viaje de su representante Oteyza logró vender libros por valor de 1.031 .505 de pesetas, repartidos en 1525 cajas y en 35.350 paquetes postales con un total de 213.340 kilos de peso.

La edición española se afianzó en el mercado americano durante la Gran Guerra por el abandono de los competidores franceses y alemanes como consecuencia del encarecimiento de la mano de obra, del papel y de la mayor dificultad en los transportes. En general, durante este período se incrementaron el

69 Vid. Palau y Dulcet, Antonio: Memorias de libreros, Barcelona, p. 198.

70 VILlaCORTA BAÑos, Francisco: Burguesía y cultura. Los intelectuales españoles en la sociedad liberal 1808-1931, Madrid, 1980, p. 220. Asimismo vid. PerEZ DE LA DeHESA, Rafael: «Editoriales e ingresos literarios a principios de siglo» en Revista de Occidente, Madrid, $\mathrm{n}^{\circ} 71$, febrero de 1969, pp. 238, nota 39. El editor Manuel Aguilar entró en la editorial de Blasco Ibañez de «chico para todo», y una de sus funciones principales era empaquetar los libros que Sempere enviaba a Hispanoamérica, donde tenía un vasto mercado. Vid. AGUILAR, Manuel: Una experiencia ..., pp. 86-106. 
volumen comercial de intercambio y de comunicaciones, pero no debido a un mayor interés de nuestras publicaciones, sino por el desabastecimiento de los países beligerantes. De hecho al final de la contienda las exportaciones disminuyeron ya que Francia recuperó su papel manteniendo un libro competitivo, a pesar de la crisis, Alemania reapareció en los mercados, y Estados Unidos cobró mayor importancia, sobre todo en México y Centroamérica. Los países importadores principales eran Argentina, Cuba y México, según los datos aduaneros y las referencias de los editores. Destaca la corriente reexportadora de libros desde el Río de la Plata al resto del Cono Sur. Parte de los envíos que recibían de España se vendían después en Chile, Paraguay y Uruguay. El segundo país era Cuba por las estrechas relaciones que siguió manteniendo con la Península después de la independencia. Otro mercado destacado fue el mexicano, aunque también recibían con intensidad las publicaciones españolas países como Perú, Chile y Uruguay. En general había demanda suficiente para la buena colocación de todas las ramas de la librería debido al escaso desarrollo de las industrias editoriales nacionales, dedicadas principalmente a la publicación de textos oficiales y libros escolares, a excepción de la argentina, debido al mayor precio del papel y de la mano de obra que en Europa. El tipo de libros que exportaban los editores españoles eran mayoritariamente libros de literatura —clásica y contemporánea-, diccionarios, enciclopedias, libros de texto y cuentos, todos ellos de gran venta. De las obras de conjunto destaca el Diccionario Enciclopédico Hispano-Americano de Literatura, Ciencias y Artes (25 volúmenes), de la editorial Montaner y Simón, por estar orientado al público hispano. De hecho en el tomo $8^{\circ}$ apareció la primera biografía del poeta Rubén Darío. Esta magna obra fue realizada entre 1887 y 1899 con gran detalle, excelentes ilustraciones y magnífica impresión. Se completó en 1910 con un segundo suplemento de tres volúmenes. Igualmente la Enciclopedia Universal Ilustrada Europeo-Americana de la casa Espasa desde su aparición en 1902 también se ocupó de temas americanos y tuvo gran éxito, aunque tenía que competir con las enciclopedias Larousse de París. Conviene destacar la falta de ediciones para América, así como la ausencia de temas y autores americanos, salvo autores muy consagrados como Rubén Darío, ya que la comunidad de idioma no significaba que tuviesen los mismos intereses y preocupaciones que los españoles. « $i \mathrm{Ha}$ pensado alguna vez el autor español en los gustos y preferencias del público que va a leerlo en América, del mercado en donde vende en mayor escala su producto, su libro?» ${ }^{71}$. Sobre la importancia de este aspecto también insistieron las memorias consulares: «creo muy conveniente indicar que los editores españoles ampliarían su negocio en esta República si incluyesen en el catálogo de sus ediciones obras de autores americanos pues no lo hacen sino por excepción» ${ }^{72}$. Las edito-

71 Pregunta del escritor y editor venezolano Blanco Fombona, Rufino: «El libro español en América», recogido en Calvo SOTELO, Leopoldo., Memoria sobre el ..., p. 46.

72 Memoria consular de Uruguay, p 5. AGA, Sección de Asuntos Exteriores, Caja n ${ }^{\circ} 1274$. 
riales españolas enviaban mayoritariamente literatura, más que libros científicos y manuales, donde únicamente destacaban Jorro, Beltrán, Salvat y Gili. «Enviamos literatura, mucha literatura, (...). El libro didáctico, el de ciencia pertenece a otros países, particularmente a Francia. (...) A los hispanoamericanos les entretenemos, pero no les enseñamos, ni les educamos. He ahí la realidad»73. En Derecho tenían gran éxito las ediciones de Reus, y las variadas publicaciones de CALPE así como las de Sopena también eran muy solicitadas. Los libros escolares y de premio de venta segura no estaban suficientemente explotados, salvo por editoriales como Hernando, Calleja, Hijos de Rodríguez (Burgos), Dalmau (Gerona) ${ }^{74}$. De hecho buena parte de los beneficios de estas casas residía en la venta de estos textos en América. Los libros españoles, según los países y los tipos'de publicaciones, solían pagar derechos arancelarios. Por este motivo los editores reclamaron a la Administración la exención de derechos para las obras hispanoamericanas y así conseguir la reciprocidad en aquellos países ${ }^{75}$. Así en México estaban libres de pagar los libros en rústica, pero los de lujo pagaban 300 pesos el kilo, en Cuba pagaban todos los libros, salvo los de texto, en Chile, Uruguay, Argentina y Paraguay estaban exentos, y en Perú y Bolivia lo estuvieron hasta 1920.

\section{LAS ESTRATEGIAS EMPRESARIALES Y LA ACCIÓN OFICIAI}

El sistema más eficaz para asentar el negocio librero en aquellos países era la apertura de sucursales si el volumen del negocio lo permitía. Las editoriales más importantes establecieron casas propias en los países americanos de mayor consumo para superar los inconvenientes de la distancia acercando el libro a los consumidores, evitando la aparición de ediciones piratas, y para eludir la existencia de intermediarios que encarecían el precio final de los libros. Además así solucionaban las resistencias que las sucursales de las casas extranjeras (Garnier, Bouret, Hachette o Appleton), establecidas en todas las capitales importantes de América, ofrecían antes de hacerse cargo de la explotación de los libros editados en España. De este modo editoriales como Calleja, Renacimiento, la Sociedad General de Librería, Sopena, CALPE (Espasa-Calpe) y la CIAP abrieron casas en Buenos Aires, primer país importador de libros españoles no sólo por su consumo interno sino por la corriente reexportadora hacia el resto del continente, sobre todo a Chile, Paraguay y Uruguay, debida a la importancia del

73 Calvo Sotelo, Leopoldo: Memoria sobre ..., p. 27.

74 Vid. MARQUeS SUREDA, S.: «Dalmau Carles. Una editorial gerundense en Sudamérica» en Delgado CriAdo, B. (Dir.): Historia de las relaciones educativas entre España y América (Coloquio Nacional de Historia de la Educación), Sevilla, 1988, pp. 420-425.

75 Vid. las conclusiones al tema II sobre «Medios prácticos para fomentar...», en Crónica de la I Asamblea ..., p. 110. Y Ministerio De TRABAJO, COMERCIO E INDUSTRIA, Compendio de conclusiones ..., p. 6.

Hispania, LXII/3, núm. 212 (2002) 1021-1058 
puerto de La Plata. La editorial Calleja en 1914 llegó a tener dieciocho delegaciones entre las repúblicas hispanoamericanas y en Filipinas ${ }^{76}$. También EspasaCalpe y la CIAP tuvieron otras sucursales en otros países como Chile, México, Cuba, Uruguay o Ecuador. Asimismo la instalación de sucursales permitía la venta de los libros al precio fijado por las casas editoriales, evitando el sobreprecio de los libreros americanos. En este sentido el editor Ruiz-Castillo señala que la apertura de la sucursal de Renacimiento en la capital argentina disgustó a los libreros porque estaban acostumbrados a vender al público a los precios que querían, en función de la disponibilidad de los libros y aprovechando el cambio de moneda. Y el cónsul de Colombia recomendaba para controlar el mercado «el establecimiento por parte de las Casas editoriales de sucursales en que se vendieran los libros al precio fijado en su cubierta». La mayoría de las editoriales modestas cedían la administración y venta de sus fondos en América, e incluso en España a corresponsales (mayoristas y libreros), o bien a otra editorial de mayor envergadura porque podían asumir los riesgos del mercado americano. Este fue el caso de la editorial Corona entre otros muchos ejemplos. La empresa formada por el escritor Pérez de Ayala y su amigo y socio capitalista, Miguel Rodríguez-Acosta en 1914, cedió la administración y distribución de su fondo en España y América a la Sociedad General Española de Librería, Diarios, Revistas y Publicaciones, S. A. ${ }^{77}$ "que tienen ya establecida una gran organización con más de 2000 corresponsales en América», y además «desean administrar libros ya publicados por personas entendidas en el asunto». Las condiciones fueron las siguientes: «(..) el $50 \%$ de descuento que les ofrecimos se refiere solamente a los libros de la guerra, pagándolos en firme y tomando ejemplares en gran número. El resto de los libros es con $50 \%$ para venderlos ellos solamente en América y les hemos puesto precios más elevados de manera que ese $50 \%$ nos deja más que el $35 \%$ en firme que damos a los libreros de Madrid ${ }^{78}$. Asimismo se comprometió por contrato con otras editoriales para

76 Vid. GARCIA PADRINO, Jaime: Libros y literatura para niños en la España contemporánea, Madrid, 1992, p. 34. Y «El libro infantil en el siglo XX» en H. EsCOLAR (Dir.), La edición moderna. Siglos XIX y XX, Madrid, 1996, p. 303.

77 Esta editorial más conocida por Sociedad General Española de Librería, filial de la casa Hachette y dirigida por M. Aguilar desde 1914 hasta 1923, organizó una amplia red de distribución y venta de periódicos y prensa en el país y América, asimismo se hizo con la concesión de los quioscos de las estaciones de ferrocarriles, que en muchos casos llegaron a ser las mejores librerías de las distintas poblaciones. Vid. Agullar, Manue: Una experiencia ..., pp. 488-565. Esta empresa se estableció en Barcelona con la compra de la Librairie Française de la Rambla, que había pertenecido a la familia Piaget desde 1845.

78 PeREZ DE AYAla, Rafael: 50 años de cartas intimas 1904-1956 a su amigo Miguel RodríguezAcosta, Madrid, 1980, p. 173, (carta fechada el 11 de junio de 1915). Pérez de Ayala estableció contacto con A. Muller, que era accionista y Director Gerente de SGEL. La Agencia General de Librería y Publicaciones de Hachette antes de establecerse en España, tenía una casa que representaba sus intereses en Irún al frente precisamente de Muller. Este recibía en Hendaya los libros y los 
administrar y distribuir sus libros como Caro Raggio, Mundo Latino, o América: «Esa sociedad, que no edita, limitándose a administrar las obras que le presentan ya editadas, se compromete por ese contrato a tomarle a Fombona (director de la editorial América) en firme cuantos libros edite cada mes»79. Es muy significativo de las características de la organización editorial española, que la mayoría de las estas pequeñas empresas, cuyos fondos gestionaba en principio la Sociedad General de Librería, pasaran a ser distribuidas por CAL$\mathrm{PE} /$ Espasa-Calpe, y fueran posteriormente adquiridas e incorporadas como secciones especializadas a la CIAP —complejo entramado editorial y distribuidor- en 1928, cuando ya estaban en clara decadencia pero mantenían el prestigio pasado de su sello. De hecho la misma CIAP llegó a gestionar los fondos de la Sociedad General de Librería para América. Otras editoriales establecían contactos con corresponsales y casas comisionistas para la distribución de sus publicaciones a las librerías. Ya en 1892 la editorial Hernando tenía una red de corresponsales en América y había concedido la exclusiva de gestión y venta de su fondo en Argentina a los intermediarios Contreras, Lazarraga y Cía.

No se genaralizaron consorcios libreros, a imitación de la casas extranjeras, que agrupasen a varias editoriales para establecer conjuntamente sucursales y depósitos de libros en las principales capitales americanas, ya que las numerosas casas pequeñas que no podían afrontar los esfuerzos, ni los riesgos que exigía el comercio librero. En vez de asociarse cedían la venta al por mayor de sus publicaciones en América a otras editoriales más importantes, como ya hemos visto. Sobre la asociación de editoriales destacan las numerosas recomendaciones hechas en las memorias consulares: «Podrían muy bien unirse para este negocio de exportación varias casas editoras de ramos diferentes, que no se hagan competencia entre si y enviar entonces una persona, que traiga muestrarios, pues hasta ahora se han vendido por carta, ignorando la presentación y la calidad del libro» ${ }^{80}$. La única iniciativa de conjunto exitosa fue la instalación en Buenos Aires del Depósito General de Representación de las editoriales Salvat, G. Gili y Sopena, en 1935 bajo la dirección de Joaquín de Oteyza, como representante exclusivo. Se colocaron doscientos cincuenta mil kilos de libros por un valor de un millón trescientas mil pesetas. Este experimentado viajante de libros por América como representante de Sopena desde 1926 pretendía consolidar estas editoriales catalanas abasteciendo el mercado rápida y racionalmente, sin necesidad de largas esperas. De esta manera una llamada de teléfono permitía que los libreros argentinos disponer en pocas horas de los títulos de estas importantes editoriales catalanas. Esta iniciativa había sido propuesta en

reexpedía a la Península y a los mercados americanos. Vid. «Vida vivida: Tiempos de cambio» en Noticias de SGEL, $\mathrm{n}^{\circ}$ 9, dic. de 1997, p. IV.

79 CANSINOS-Assens, Rafael: La novela de un literato, 2 (1914-1923), Madrid, 1995, pp. 127 y 267.

80 Memoria consular de Guatemala, p. 3. AGA, Sección de Asuntos Exteriores, Caja n ${ }^{\circ} 1274$. 
las memorias consulares a los editores españoles ${ }^{81}$. Las dificultades que acompañaban la exportación librera revelan la débil organización comercial de la industria editorial española frente a las europeas, más modernas y racionales. De hecho los editores y libreros acometían la aventura americana individualmente, resultando más compleja. En las condiciones analizadas no resultaba rentable el comercio con América, y explica la insuficiente introducción de la industria española en aquellos países. Las iniciativas particulares, aunque asentaron la edición española en las repúblicas hispanoamericanas, no resolvieron los problemas principales (retraso de los envíos, demora en los pagos, ediciones clandestinas,... etc.) que afectaban al comercio librero. La importancia del mercado, los problemas en la distribución y venta de libros, y la competencia extranjera pusieron de manifiesto la necesidad de crear una asociación de editores y libreros, que abordase conjuntamente la exportación del libro español. El objetivo de esta organización colectiva sería el establecimiento de un gran centro distribuidor o de varios en las principales capitales americanas para reducir gastos y conseguir eficazmente la colocación de los libros en los mercados hispanos. De este modo se racionalizaría la exportación de libros a América, atendiendo a criterios de mercado y no a las rigideces de las compras en firme, ni a las falsas expectativas que originaba el servicio de novedades. $Y$ para conseguir un mayor éxito y difusión se encargaría de realizar una propaganda común: «Lo más elemental de cuanto deberían hacer las editoriales españolas sería centralizar sus exportaciones a América y crear en cada país un depósito de la totalidad de sus libros. Así estaría atendido el mercado con el mínimo de gastos y se evitarían los quebrantos de las remesas directas a los libreros y los gastos particulares de cada una de las empresas que poseen depósito en población americanas» ${ }^{82}$.

Muchos fueron los diversos intentos y proyectos a realizar desde fines del siglo XIX hasta los años 30, pero fracasaron por problemas financieros y por la desconfianza de la mayoría de editores hacia un depósito que reuniera las obras de todas las editoriales españolas, convencidos de la competencia negativa que supondría para sus fondos editoriales. Sobre el escaso sentido colectivo de la industria librera destaca la experiencia de Ruiz Castillo al frente de Renaci-

81 «El proyecto consiste en que los editores españoles nombrasen Agente exclusivo a una persona residente en Santiago o en Valparaíso, remitiéndole sus obras en depósito. Este Agente los vendería al precio marcado por las casas editoras, con el recargo correspondiente con relación al cambio, y una muy pequeña comisión, que unida al descuento que conceden los editores, bastaría para sufragar los gastos de la tienda, reparto, etc. Esta misma casa se encargaría de remitir a cada una de las librerías más importantes del país los libros y revistas con el descuento acostumbrado, recibiendo a su vez, de las casas editoriales, un pequeño extra de descuento». En Memoria consular de Chile, s/p. AGA, Sección de Asuntos Exteriores, Caja nº 1274.

82 VENEGAS, José: El problema ..., p. 101.

126 «El comercio del libro español». Charla del editor y Presidente de la Cámara Oficial del Libro, Ruiz-Castillo, en la Escuela de Librería, en Bibliografía General ..., octubre de 1932, p. 133. 
miento, quien tuvo que recurrir a la Casa Garnier de París para conseguir la lista y los datos de los principales libreros americanos porque los editores españoles guardaban esta información celosamente ${ }^{83}$. Además la excesiva atomización de la industria editorial había impedido coordinar una acción colectiva de estas características. De hecho las únicas iniciativas hechas realidad, el Sindicato Exportador del Libro Español (SELE), impulsada por un grupo de editores madrileños en 1930 para organizar conjuntamente la exportación de libros, y el Consorcio Exportador del Libro Español constituido en Barcelona con el mismo fin no consiguieron agrupar a la totalidad de los editores y libreros del país. Por otra parte los intereses de los antiguos corresponsales e intermediarios ya establecidos no contribuían al desarrollo de esta organización comercial, que reduciría su función. El 14 de marzo de 1930 se constituyó el Sindicato Español del Libro Español, S. A. con un capital de 2.000.000 de pesetas, en respuesta al apartado L1 del artículo $8^{\circ}$ del Decreto-ley del 23 de julio de 1925 -orgánico de las Cámaras Oficiales del Libro-, que instaba a la creación de sindicatos u organizaciones especiales de venta para la exportación del libro en el extranjero, singularmente en los países de habla hispana. También respondía al artículo 24 del R. D. del 24 de agosto de 1928, que aprobaba el reglamento del Comité Regulador del Papel. En dicho artículo se fijaba que tan sólo recibirían primas a la exportación aquellos editores que perteneciesen a un sindicato o consorcio constituido con el fin de difundir el libro español en los países hispanoamericanos y en Filipinas. Aunque en principio se pretendía crear una entidad controlada y protegida por el Estado en relación con el R. D. del 12 de enero de 1926, regulador de los sindicatos industriales y mercantiles, el SELE se constituyó como sindicato puramente comercial, ajeno a la protección oficial, e integrado por la asociación voluntaria de autores y editores para la organización de mercados, y la distribución rápida y económica del libro español en América. Pretendía crear una potente red distribuidora en todo el continente americano, así como un sistema intenso de propaganda, y facilitar el crédito necesario al comercio librero. Para lograr estos objetivos era necesario la centralización del servicio de compra-venta de publicaciones y la instalación de delegaciones y sucursales directas. También se encargaría conjuntamente de la defensa de la propiedad intelectual, de la difusión bibliográfica, y de la percepción de las primas a la exportación. Llegó a tener una delegación en Buenos Aires, aunque su intención era establecerse en Cuba, México, Colombia y Estados Unidos. Abrió cuentas corrientes a los clientes, y estableció un servicio de novedades en firme y depósito ${ }^{84}$. Esta entidad diseñó una política comercial moderna, racional y con vocación colectiva, pero tan sólo logró agrupar a una minoría. No

126 «El comercio del libro español». Charla del editor y Presidente de la Cámara Oficial del Libro, Ruiz-Castillo, en la Escuela de Librería, en Bibliografía General ..., octubre de 1932, p. 133.

84 Vid. «advertencias importantes sobre el uso de nuestro Catálogo núm. 1» en Catálogo del Sindicato Exportador del Libro Español, S. A. (SELE), nº 1, Madrid, 1933?, s/p. 
pasaban de 15 los editores asociados cuando en Madrid había 140 editores registrados. Los miembros fundadores de esta sociedad exportadora fueron las editoriales: Reus, S. A., Bailly-Baillère, S. A., Castro, S. A., Voluntad, S. A., Esteban Dossat, Estampa, Albero, Atenea, S. A., La Nave, Alier (musical), la Librería y Editorial Madrid, S. A., y la Librería Internacional Romo. Después se sumaron la editorial Calleja, S. A., la Librería Bosch y la Academia de Ciencias Morales y Políticas. En la primera memoria del Sindicato, tras ocho meses de actuación había logrado un total de 407.250,15 pesetas en las ventas al contado, en firme y en comisión. Tras pagar los gastos generales y de propaganda el balance del negocio arrojó unos beneficios que se destinaron al reparto de un dividendo del $6 \%$ al capital desembolsado en las acciones suscritas, un $35 \%$ al fondo de amortización y un $13 \%$ al Consejo de administración ${ }^{85}$. Sobre el propósito del SELE conviene destacar las palabras de su mentor, el editor y Presidente de la Cámara Oficial del Libro de Madrid, Julián Martínez Reus, quien afirmaba que todo lo que no fuese una acción colectiva, amplia y ordenada estaba condenado al fracaso porque con el concurso individual se desaprovechaban muchos mercados: «organizar nuestra venta en España y, sobre todo, en América. Para ello bastaría con establecer en cada República de habla española una casa filial con venta directa, desde luego, lo cual, a más de regularizar el precio del libro - sometido allí casi siempre al capricho del vendedor- podría servir para fijar el descuento único y para ofrecer en todo momento existencias de nuestros fondos editoriales sin tener que aguardar los largos plazos que exige el envío desde España» ${ }^{86}$.

Las constantes quejas de libreros y editores, aunque reales, también estaban encaminadas a conseguir el respaldo oficial y financiero estatal en la organización del comercio con América. Aparte de la concesión temporal de las primas a la exportación y el apoyo a la creación del SELE y del Consorcio Exportador del Libro Español, los poderes públicos no se ocuparon del problema hasta 1935 con la II República, pero entonces el Estado pretendía asumir la sistematización de la exportación ante la incapacidad de la iniciativa privada. En este sentido destaca la creación del Instituto del Libro Español por R. O. del 27 de abril de 1935, que supuso la culminación de la reclamada política del libro. Este Instituto, dependiente del Ministerio de Instrucción Pública y Bellas Artes, apareció en respuesta a las necesidades derivadas del proyecto de instalar depósitos de libros en Hispanoamérica, según Orden del 1 de marzo de 1935, para racionalizar el comercio con aquellos mercados. Pero, por un nuevo Decreto reglamentario del 1 de agosto, se convirtió en «un organismo encargado

85 Vid. «S.E.L.E., Sindicato exportador del Libro español» en La Gaceta de las Artes ..., agosto de 1931, pp. 34 y 35. Y los artículos «Sindicato Exportador del Libro Español, S. A., Madrid», junio de 1930, p. 42. «La exportación del libro español», febrero de 1929, p. 41.

86 «Hablando con el Presidente de la Cámara Oficial del Libro» en Bibliografía General ..., septiembre de 1928, p. 99. Reproduce una entrevista realizada por Pedro Massa para la revista De España Comercial. 
de la tutela económica y cultural del libro». Amplió sus funciones y reguló el establecimiento de los mencionados depósitos a través de la Junta rectora. Asimismo asumió otras actividades en favor de la expansión del libro español, y complementarias a la instalación de los depósitos libreros como la formación y difusión de la bibliografía en castellano, la elaboración de la estadística comercial de la producción, el control del registro de autorizaciones y contratos entre autores y editores, la vigilancia de los tratados de propiedad intelectual, y por último la organización de ferias y exposiciones en el extranjero, como la que se había celebrado en Buenos Aires con gran éxito en $1933^{87}$. En definitiva, pretendía «suscitar y apoyar la mejora técnica y artística de la producción del libro español» auxiliando directa o indirectamente la iniciativa privada. Este Instituto pretendía paliar las dificultades que obstaculizaban la distribución y venta de libros evitando la aparición de publicaciones clandestinas, y agilizando los cobros de los pedidos, cuestión endémica pero agravada tras la suspensión de pagos de muchos países hispanoamericanos como consecuencia de la crisis económica de 1929. Aunque nació con vocación coordinadora y organizativa pretendía intervenir en la exportación de libros, muy a pesar de los editores y libreros. Esta situación explica las fricciones surgidas con la Cámaras Oficiales del Libro, tras la satisfacción inicial con que fue recibida la propuesta gubernamental ${ }^{88}$. Las protestas respondían, en primer lugar, a la escasa representación de la propia Cámara siendo una corporación oficial en la Junta del Instituto, así como del gremio de editores y libreros en particular. Reclamaban mayor protagonismo de las Cámaras de Madrid y Barcelona, en la organización de los depósitos, ya que en última instancia esta tarea correspondería a las Cámaras, y no al Estado. En este sentido manifestaron su disconformidad con la organización comercial del Instituto porque recelaban del intervencionismo estatal en la exportación de libros. Las actividades del ILE debían ser principalmente de asesoramiento y de respaldo económico a imitación del desaparecido Comité Oficial del Libro (1920-1929), que tan estrechamente había colaborado en los trabajos de las Cámaras. Consideraban que este organismo debía ayudar a los editores y libreros en la conquista del mercado americano, pero sin intervenir directamente, dejando a los profesionales del libro - agrupados en las Cámaras del Libro- que desarrollaran las cuestiones comerciales, ya que estaban más capacitados y poseían más experiencia. De este modo el Instituto se encargaría de informar sobre las leyes de propiedad intelectual de cada país y sobre la situación del mercado librero en América. Y contribuiría en la elaboración de

87 Vid. «La Exposición del Libro Español en Buenos Aires» en Bibliografía General ..., julio y agosto de 1933, pp. 137-140. Y en noviembre del mismo año, p. 187. Asimismo destaca la detallada información fotográfica y de prensa sobre este acontecimiento, recogida en Exposición del Libro Español, AGA, Sección de Asuntos Exteriores, Libro n ${ }^{\circ} 4214$.

88 Vid. «Los depósitos de libros en América. Informe de la Cámara Oficial del Libro de Madrid» en Bibliografía General ..., marzo de 1935, pp. 37-42. Recoge las propuestas de los editores y libreros al proyecto de instalar depósitos en América con anterioridad a la creación del ILE.

Hispania, LXII/3, núm. 212 (2002) 1021-1058 
catálogos y bibliografías de obras en castellano realizadas por la Cámara Oficial, y a la organización de ferias y exposiciones del libro español en el extranjero ${ }^{89}$. El Instituto nació relacionado con el comercio librero en América pero, intentó abarcar todo el mundo del libro. «El Instituto del Libro Español, creado por Decreto de 27 de abril último, no responde plenamente a la idea motivadora de la Orden de $1^{\circ}$ de marzo, a la que preténdiose servir. El libro español se halla necesitado de una tutela del Estado que abata obstáculos, acreciente su difusión y asegure el rendimiento económico a que tienen derecho autores y editores ${ }^{90}$. De esta manera se le atribuyeron funciones que eran competencia de las Cámara del Libro desde su creación. La entidad más antigua reclamaba la organización de los depósitos de librós en función de su experimentada acción en favor de la difusión del libro. Y el nuevo Instituto encargado de realizar esa función pretendía dirigir toda la actividad relacionada con la industria del libro, dejando sin razón de ser a la propia Cámara. Por otra parte eran dos organismos que respondían a con concepciones distintas. La Cámara era una corporación de profesionales del libro que colaboraba con el Estado y tenía respaldo oficial. Y el Instituto era un organismo estatal encargado de la política del libro que pretendía colaborar con los editores y libreros. De este modo el enfrentamiento también reproducía un conflicto entre la iniciativa privada y el Estado. Los editores y libreros se habían mostrado incapaces de sistematizar el comercio con América. De ahí las constantes quejas y escritos enviados a los Ministerios de Comercio y de Estado solicitando ayuda para superar los numerosos obstáculos que entorpecían dicho comercio. Pedían respaldo económico e institucional pero, cuando el Estado intervino para regular la situación se opusieron. Ante esta situación los editores reconocieron las actividades del ILE en relación con la política del libro en el extranjero, pero reivindicaron para las Cámaras la labor de difusión y propaganda del libro en España. El editor Manuel Aguilar llegó a reclamar el restablecimiento de las primas a la exportación en lugar de la actuación del Instituto, aunque por el contrario Enrique BaillyBaillière creía que los depósitos eran más convenientes porque acercaban los libros a los clientes. Aunque en principio se eligió México como primer centro distribuidor en el continente americano de las publicaciones españolas, se desestimó porque los editores argumentaron que era un mercado saneado y no necesitaba la intervención estatal, además la instalación de este depósito perjudicaría notablemente a los libreros y corresponsales allí establecidos ${ }^{91}$. De

89 Vid. la Junta Directiva de la Sección de Libreros de Nuevo celebrada el 6 de febrero de 1936, en Bibliografía General ..., febrero, pp. 29 y 30.

90 Disposición del 1 de agosto de 1935, aparecido el 3 en La Gaceta de Madrid.

91 Vid. la Junta directiva de la Sección de Editores de la Cámara Oficial de Madrid del 9 de agosto de 1935, y la Sesión del 21 de noviembre de 1935 de la Cámara Oficial de Barcelona en Bibliografía General ..., julio-agosto, p. 114, y diciembre de 1935, pp. 181 y 182 . Todas las editoriales catalanas, un total de 40 (Juventud, Labor, Sopena, Gili, Salvat, Maucci..., etc.) se negaron al establecimiento de un depósito en Méjico. 
hecho los libreros mexicanos se constituyeron en Asociación para hacer frente a la creación a cargo del ILE de un depósito conjunto de las editoriales españolas. Finalmente se decidió establecer un depósito en Lisboa como campo de experiencia y otro en Santiago de Chile, vivero de ediciones piratas, después de descartar la posibilidad de colocarlo en Perú. Pero, la guerra impidió que la instalación de los depósitos se hiciese realidad. Otra queja muy extendida por parte de los editores modestos contra las condiciones fijadas por el ILE era la de no admitir remesas de libros por valor inferior a 25.000 pesetas, y la solución propuesta de asociarse tampoco gustaba a los afectados, dado su marcado individualismo ${ }^{92}$.

92 Vid. Junta general de Editores celebrada el 24 de agosto de 1935, en Bibliografía General ..., p. 115 .

Hispania, LXII/3, núm. 212 (2002) 1021-1058 